\title{
O MERCADO DA SOJA NO BRASIL E NA ARGENTINA: SEMELHANÇAS, DIFERENÇAS E INTERCONEXÕES ${ }^{1}$
}

\author{
THE SOY MARKET IN BRAZIL AND ARGENTINA: SIMI- \\ LARITIES, DIFFERENCES AND INTERCONNECTIONS
}

Valdemar João Wesz Junior ${ }^{2}$

RESUMO: Ao longo das últimas décadas, a soja tornou-se a principal atividade agropecuária no Brasil e na Argentina, tanto em termos territoriais (área plantada) como econômico-comerciais (valor das exportações). O objetivo deste artigo é analisar as dinâmicas, os processos e os atores envolvidos na cadeia produtiva da soja no Brasil e na Argentina, destacando as semelhanças, diferenças e interconexões desse mercado nos dois países. Além da consulta à literatura acadêmica especializada na discussão dos temas abordados, utilizam-se dados estatísticos de fontes oficiais. Paralelamente, foram coletadas informações em materiais midiáticos, especialmente jornais e revistas, além de um levantamento nos relatórios, boletins institucionais e balanços particulares das empresas. Os resultados apontam que, apesar das diferentes e particulares trajetórias econômicas, políticas, científicotecnológicas e jurídico-institucionais de cada país, o mercado da soja no Brasil e na Argentina apresenta uma forte similaridade, que fica evidente na expansão do grão para novas regiões, na concentração nos grandes produtores rurais, na presença das mesmas empresas transnacionais e no destinado majoritário da produção para exportação.

Palavras-chave: mercado da soja, sistema agroalimentar, Brasil, Argentina.

\footnotetext{
${ }^{1}$ Este artigo é resultado parcial da tese de doutorado do autor (Wesz Junior, 2014). O autor agradece ao prof. Dr. Sergio Pereira Leite pela orientação da tese e ao Conselho Nacional de Desenvolvimento Científico e Tecnológico (CNPq) e à Fundação de Amparo à Pesquisa do Estado do Rio de Janeiro (Faperj) pela bolsa de estudos.

${ }^{2}$ Professor Adjunto da Universidade Federal da Integração Latino-Americana (UNILA). Doutor em Ciências Sociais pelo Programa de Pós-Graduação de Ciências Sociais em Desenvolvimento, Agricultura e Sociedade na Universidade Federal Rural do Rio de Janeiro (CPDA/UFRRJ) e pesquisador vinculado ao Observatório de Políticas Públicas para Agricultura (OPPA/CPDA/ UFRRJ), Rio de Janeiro, RJ, Brasil, e-mail: jwesz@yahoo.com.br.
} 
ABSTRACT: During the last decades soy has become the main farming activity in Brazil and Argentina either in territorial (planted area) or economic-commercial (value of exportation) terms. This article aims at analyzing the dynamics, processes, and actors involved in the soy productive chain in Brazil and Argentina, highlighting similarities, differences and interconnections in both countries. Statistical data from official sources and academic literature specialized in the discussion of the themes were used in this paper. Also, it draws on information collected in media material, especially newspapers and magazines, and a gathering of reports, institutional bulletins and private balance sheets form the companies. Results point to a similarity in the soy markets of Brazil and Argentina, in spite of different and specific economic, political scientific, technological, juridical, institutional trajectories. This similarity is evident when seeing the grain's expansion to new regions, concentration in large rural producers, presence of the same transnational companies and produce predominantly intended for export.

Keywords: soy market; agro-food system, Brazil, Argentina.

\section{INTRODUÇÃO}

As atividades agropecuárias exerceram, historicamente, grande importância na economia brasileira e argentina. Apesar do processo de urbanização e industrialização, esse segmento manteve uma forte expressividade econômica, comercial e territorial (Banco Mundial, 2014). No Brasil, o "Produto Interno Bruto (PIB) do agronegócio" (que inclui a indústria de insumos e equipamentos, a produção primária e indústria de processamento e distribuição) alcançou $22,8 \%$ do PIB nacional, e as exportações agroalimentares foram responsáveis por US\$ 100 bilhões em 2013 (41,3\% do total) (CEPEA, 2014; SECEX, 2014). Na Argentina, o PIB agropecuário ${ }^{3}$ equivale a $10 \%$ dos valores totais, e o setor agroalimentar respondeu por mais de 50\% das exportações em 2010 (Lissi e Losi, 2010; Gras, 2013).

Esse desempenho do setor agroalimentar conta com uma im-

${ }^{3}$ Diferentemente do Brasil, na Argentina não estão disponíveis cálculos do "PIB do agronegócio". 
portante contribuição do complexo soja (grão, óleo e farelo), que se tornou a principal atividade agropecuária em ambos os países, desbancando cultivos tradicionais, como trigo, milho e pecuária na Argentina e o café e o açúcar no Brasil. Atualmente, o Brasil é o maior exportador mundial de soja em grão e, segundo o United States Department of Agriculture (USDA, 2014), pode tornar-se o maior produtor nas próximas safras (que é liderado pelos Estados Unidos). Essa oleaginosa tem sido considerada o cultivo de maior envergadura da agricultura brasileira pela sua importância territorial (27,7 milhões de hectares plantados em 2012/13, o que equivale a 52\% dos cultivos temporários) e econômico-comercial (9,4\% das exportações totais de 2012) (CONAB, 2013; SECEX, 2013). Na Argentina, a soja ocupava cerca de $60 \%$ da área agrícola plantada e respondia por $25 \%$ do valor total das vendas ao comércio exterior em 2010 (o país é líder mundial nas exportações de farelo e óleo e o terceiro maior produtor de soja) (Faostat, 2013; INDEC, 2013). Além disso, essa cadeia representa 30\% do PIB do setor agroindustrial argentino (Hilbert, 2012).

Diante da importância e da magnitude desse mercado, o objetivo deste artigo é analisar as dinâmicas, os processos e os atores envolvidos na cadeia produtiva da soja no Brasil e na Argentina. Paralelamente, procura-se destacar as semelhanças, diferenças e interconexões do complexo soja (grão, óleo e farelo) entre esses países. Além da utilização de uma literatura acadêmica especializada, foram utilizados dados estatísticos de fontes oficiais brasileiras - Agência Nacional do Petróleo, Gás Natural e Biocombustíveis (ANP), Associação Brasileira das Indústrias de Óleos Vegetais (ABIOVE), Companhia Nacional de Abastecimento (CONAB), Instituto Brasileiro de Economia e Estatística (IBGE), Instituto Mato-Grossense de Economia Agropecuária (IMEA), Ministério da Agricultura, Pecuária e Abastecimento (MAPA) e Secretaria de Comércio Exterior (SECEX) - e argentinas - Ministerio de Agricultura, Ganadería y Pesca (MAGyP), Instituto Nacional de Estadística y Censos (INDEC), Instituto Nacional de Tecnologia Agropecuária (INTA), Camara de la Industria Aceitera de la Republica Argentina (CIARA), Ministerio de Economia y Finanzas Publicas (MECON) e Oficina Nacional de Control Comercial Agro- 
pecuario (ONCCA). Paralelamente, foram coletadas informações em materiais midiáticos, especialmente jornais e revistas, relatórios, boletins institucionais e balanços particulares das empresas.

Após esta Introdução, é analisado separadamente o mercado da soja no Brasil e na Argentina, destacando o seu processo de expansão, o destino da produção e os principais atores envolvidos. Em seguida, realiza-se uma comparação entre os dois países, evidenciando as similaridades, diferenças e interfaces referentes às dinâmicas encontradas, os processos em curso e os atores presentes. Por fim, são trazidos alguns elementos conclusivos.

\section{O MERCADO DA SOJA NO BRASIL}

A soja começou a ser cultivada no Sul do Brasil em 1900, mas, até a metade do século XX, tinha como destino a produção de forragem para alimentação do gado leiteiro e para a criação de suínos em pequenas propriedades rurais. Com o estabelecimento do programa oficial de apoio à triticultura nacional, em meados dos anos 1950, a soja passou a ser incentivada como cultivo de rotação com o trigo, que é plantado no inverno. Segundo a Empresa Brasileira de Pesquisa Agropecuária (Embrapa, 2004), tratava-se da melhor alternativa tanto do ponto de vista técnico (leguminosa sucedendo gramínea) quanto econômico (melhor aproveitamento da terra, das máquinas, dos implementos, da infraestrutura e da mão de obra). Até os anos 60 , a soja atuava como coadjuvante. A partir de então começa a se estabelecer como um cultivo economicamente importante, tendo sua produção se multiplicado por cinco (passou de 206 mil toneladas em 1960 para um milhão de toneladas em 1969). Desse montante, 98\% localizavam-se nos três estados meridionais (Embrapa, 2004).

Entretanto, foi na década de 1970 que o crescimento da soja se tornou mais expressivo, com a expansão da área cultivada, que saltou de 1,3 milhão para 8,8 milhões de hectares, e da produção, que passou de 1,5 milhão para mais de 15 milhões de toneladas (Figura 1). Diversos elementos condicionaram esse resultado: aumento do preço internacional (principalmente pela quebra de safra na Rússia 
e na China); crescente demanda por óleos vegetais em substituição às gorduras animais; surgimento de um sistema cooperativista dinâmico, que apoiou fortemente a produção, industrialização e comercialização das safras; construção de uma rede de pesquisa sobre a soja; melhorias nos sistemas viário, portuário e de comunicações, facilitando o transporte e barateando os custos das exportações; estabelecimento de um importante parque industrial de máquinas, de insumos agrícolas e de processamento de oleaginosas; incentivos fiscais ao cultivo do trigo; aumento da demanda interna, proveniente da crescente urbanização e da mudança nos hábitos alimentares da população brasileira; e subsídios à exportação sob a forma de isenções, créditos fiscais e taxas de juros favorecidos (Bickel, 2004; Embrapa, 2004; Campos, 2012).

Figura 1 - Área cultivada (em mil hectares) e produção de soja (em mil toneladas) no Brasil (1961/62 a 2012/13)

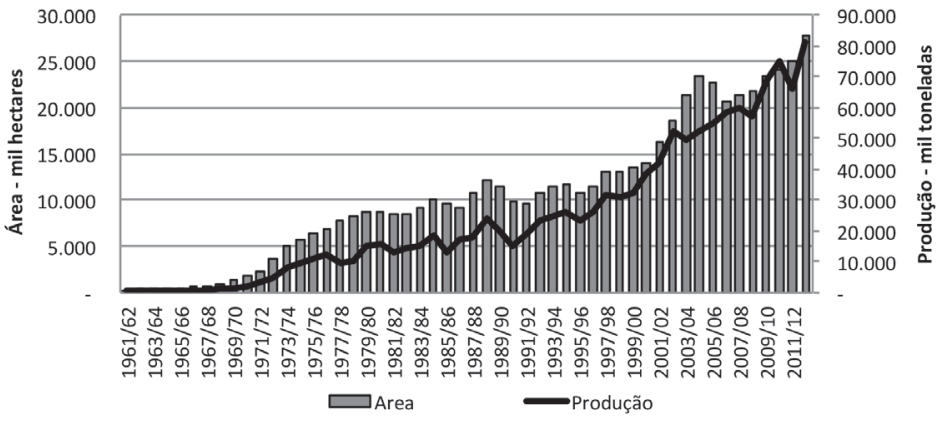

Fonte: CONAB (2013).

Para além dos elementos já destacados, é preciso considerar que a política econômica brasileira na década de 1970 mantinha como estratégia predominante o padrão nacional-desenvolvimentista, voltado prioritariamente à industrialização do país a partir da substituição das importações, momento em que o Estado assumia um papel intervencionista e financiava suas próprias ações por meio de fundos obtidos com as instituições internacionais de crédito (Delgado, 2005). Neste período, a agricultura, que passava por uma intensa modernização, estava ancorada em duas políticas fundamentais: i) 
Sistema Nacional de Crédito Rural (SNCR), que financiava custeio, investimentos e comercialização da produção; e ii) Política de Garantia de Preços Mínimos (PGPM), que definia um preço base antes do plantio. A soja beneficiou-se de ambas as políticas, seja por meio de incentivos diretos ao cultivo (crédito subsidiado, inovação tecnológica, preços mínimos etc.) ou indiretos (modernização dos setores de processamento e dos canais de distribuição e desenvolvimento de segmentos industriais fornecedores de insumos e máquinas) (Belik, 1995; Leite, 2001; Wedekin, 2005; Campos, 2012).

No início dos anos 80, não houve grande crescimento no cultivo da soja no Brasil, devido principalmente à queda do preço internacional e pela crise econômica nacional. Mas, da metade da década em diante, a retomada do preço motiva uma nova ampliação da área cultivada, que alcançou o recorde de 12,2 milhões de hectares na safra 1988/89 (valor que só foi superado nove anos depois). É importante destacar que esse aumento da superfície plantada não ocorreu na Região Sul do país, que de 1977/78 a 1987/88 manteve sua área estável. A expansão aconteceu, sobretudo, nas áreas de cerrado (nos estados da Região Centro-Oeste, da Bahia e de Minas Gerais), que passaram a representar, aproximadamente, $40 \%$ da produção total (Bickel, 2004). Um fator fundamental para esse resultado foi o estímulo que o governo militar concedeu à "ocupação do cerrado" e à expansão da fronteira agrícola, visto que o país adotou uma estratégia de gerar divisas e equilibrar sua balança comercial por meio do aumento de suas exportações. Vários programas foram criados para cumprir essa finalidade, dentre os quais se destacaram o Programa de Desenvolvimento dos Cerrados (Polocentro) e o Programa de Cooperação Nipo-Brasileiro para o Desenvolvimento do Cerrado (Prodecer).

O Polocentro (1975-1980) tinha como objetivo "promover o rápido desenvolvimento e a modernização das atividades agrícolas no Centro-Oeste brasileiro. Por meio deste programa, o governo federal buscou fortalecer a infraestrutura dessas áreas de forma que elas servissem de polos de desenvolvimento para a agricultura no cerrado" (Queiroz, 2004). Entre 1977 e 1979, cerca de 3,7 milhões de hectares foram beneficiados pelo Polocentro, com investimentos 
diretos em rodovias, armazenagem, rede elétrica, incentivos fiscais, recursos para pesquisa agropecuária e assistência técnica. Segundo Warnken (1999), o Programa foi direcionado principalmente para as grandes e médias propriedades rurais, visto que apenas $10 \%$ das linhas de crédito destinaram-se aos estabelecimentos com área inferior a 200 hectares. O Polocentro viabilizou a incorporação de quase 2,5 milhões de hectares à agricultura intensiva e à pecuária, sendo a soja um dos cultivos mais beneficiados (Warnken, 1999).

O Prodecer, por sua vez, foi criado em 1979, dentro do II Plano Nacional de Desenvolvimento, e visava fortalecer a ocupação do Cerrado com bases técnicas e gerenciais modernas, por intermédio de um acordo firmado entre o Brasil e o Japão para a produção de soja no Cerrado, visto o interesse do país asiático na importação da oleaginosa. Um de seus objetivos foi o assentamento de agricultores do Sul e Sudeste do país que tivessem experiência no uso de tecnologias e que apresentassem vínculos com as cooperativas agrícolas ou associações de produtores rurais (Inocêncio e Calaça, 2009). O Prodecer foi implementado em três fases, cobrindo os Estados de Minas Gerais, Mato Grosso do Sul, Mato Grosso, Goiás, Bahia, Tocantins e Maranhão, onde foram realizados 21 projetos com 758 assentados, incorporando 353.748 hectares de Cerrado ao processo produtivo (Warnken, 1999).

Além do Polocentro e do Prodecer, outros fatores potencializaram a expansão da soja para o Centro-Norte brasileiro: o desenvolvimento de cultivares adaptadas ao cerrado; a geração de tecnologias voltadas ao melhoramento do solo; o regime pluviométrico favorável aos cultivos de verão; as políticas de incentivos fiscais e de concessão de terras para aberturas de novas áreas; o baixo valor das terras na década de 1970 e 1980; a topografia favorável ao uso de máquinas e equipamentos; a melhoria no sistema de escoamento da produção, com o estabelecimento de novos corredores de exportação, utilizando rodovias, ferrovias e hidrovias; a chegada das agroindústrias na região; a experiência dos produtores do Sul do país na produção de soja; e o não reconhecimento dos direitos sobre os territórios tradicionalmente ocupados por posseiros, pequenos produtores, povos indígenas e extrativistas (Warnken, 1999; Embrapa, 2004; Fernández, 2009). 
Da safra 1995/96 até 2004/05, houve um crescimento praticamente ininterrupto da área cultivada com o grão, período que ficou conhecido como o "boom da soja" no Brasil, alcançando mais de 23 milhões de hectares, o que significa que em dez anos a superfície plantada dobrou. Além do aumento da demanda e do preço internacional, foi fundamental para essa expansão a mudança na política econômica, que em 1999 desvalorizou o câmbio e reeditou a política de geração de saldos comerciais ancorados na exportação de produtos primários (Delgado, 2005). Conforme Brandão, Rezende e Marques (2006), após a desvalorização cambial, houve um aumento da produção de soja baseado na expansão da área cultivada (principalmente em novas áreas de Cerrado e Amazônia) e não no crescimento da produtividade, como ocorreu no período anterior.

Com a redução do preço, de 2006 a 2007, deixam de ser cultivados dois milhões de hectares de soja. Entretanto, nas safras seguintes, há uma nova retomada em termos de produção e área, alcançando 81,2 milhões de toneladas e 27,7 milhões de hectares crescimento de $34 \%$ e $39 \%$, respectivamente, de 2006/07 a 2012/13 (Figura 1). Nesse intervalo de sete safras, o preço da soja alcançou recordes históricos, e a demanda internacional (principalmente dos países asiáticos) cresceu a passos largos. Também foi fundamental para esse avanço as inovações tecnológicas, tais como o uso de sementes melhoradas, plantio de precisão, novos insumos etc.

Para Heredia, Palmeira e Leite (2010), a intervenção do Estado tem sido fundamental nas transformações da agropecuária brasileira. Ao contrário do que a leitura corrente afirma ao ressaltar o mito do pioneiro externo, os autores argumentam que as mudanças operadas no "agronegócio" a partir do final dos anos 80 e durante todo período seguinte não foram exclusivas da iniciativa privada, tendo sido influenciadas pela política econômica, de crédito rural, de ordenamento territorial, ambiental, de infraestrutura etc.

Apesar de o crédito rural ter reduzido a sua importância no final da década de 1980 e durante toda década de 1990 (momento em que as políticas de comercialização ampliaram a sua atuação), nos últimos anos, ocorreu uma nova ampliação desta modalidade 
de financiamento público para a produção agrícola. O crédito rural destinado ao custeio da produção de soja passou de R $\$ 1,4$ bilhão em 1999 para R \$ 12,2 bilhões em 2012, respondendo neste último ano por $35 \%$ do valor total concedido ao custeio agrícola, sendo o cultivo com maiores incentivos. A participação da soja é ainda maior em Mato Grosso, que absorve dois terços do montante total destinado ao crédito rural, restando um pouco mais de $30 \%$ para os demais produtos agrícolas no estado (BCB, 2013).

A Figura 2 demonstra o intenso processo de espacialização da produção de soja nos últimos 40 anos por microrregião brasileira. Ao longo desse período, ficam evidentes dois processos correlatos: a expansão para novas regiões e a intensificação em algumas áreas mais "tradicionais". No que se refere à expansão, é evidente o avanço do cultivo ao longo dos anos. Na safra de 1972/73, a soja encontrava-se no Sul do país, além de São Paulo, Minas Gerais, Mato Grosso do Sul e Goiás. Em 1980/81, já se pode ver a presença em Mato Grosso, Tocantins, Maranhão e Bahia e, no início do século XXI, em Rondônia, Amazonas, Pará e Piauí. Na safra de 2010/11, Acre e Roraima passam a fazer parte do grupo, restando "fora" do cultivo da soja na Região Norte apenas o Amapá. Em suma, além do avanço sobre as áreas de Cerrado nos estados do Centro-Oeste, Nordeste e Minas Gerais, é evidente a sua expansão na região amazônica. A Figura 2 também evidencia uma ampliação da área cultivada no Sul do país, principalmente na última década, mostrando que, inclusive nas regiões mais "tradicionais", ocorreu uma nova fase de expansão da soja.

As microrregiões com maior concentração na superfície cultivada com soja (cor mais escura no mapa) também foram ampliadas. Enquanto que na safra de 1972/73 a maior concentração se localizava principalmente no Noroeste do Rio Grande do Sul, em 2010/11 estava difundida em muitas regiões brasileiras, abrangendo grande parte dos Estados de Mato Grosso e do Paraná, Sul goiano, Oeste baiano, fronteira entre Maranhão, Piauí e Tocantins (corriqueiramente chamada de Mapito), Noroeste gaúcho, fronteira entre Goiás e Minas Gerais e a faixa central de Mato Grosso do Sul. 
Figura 2 - Área cultivada com soja por microrregião no Brasil

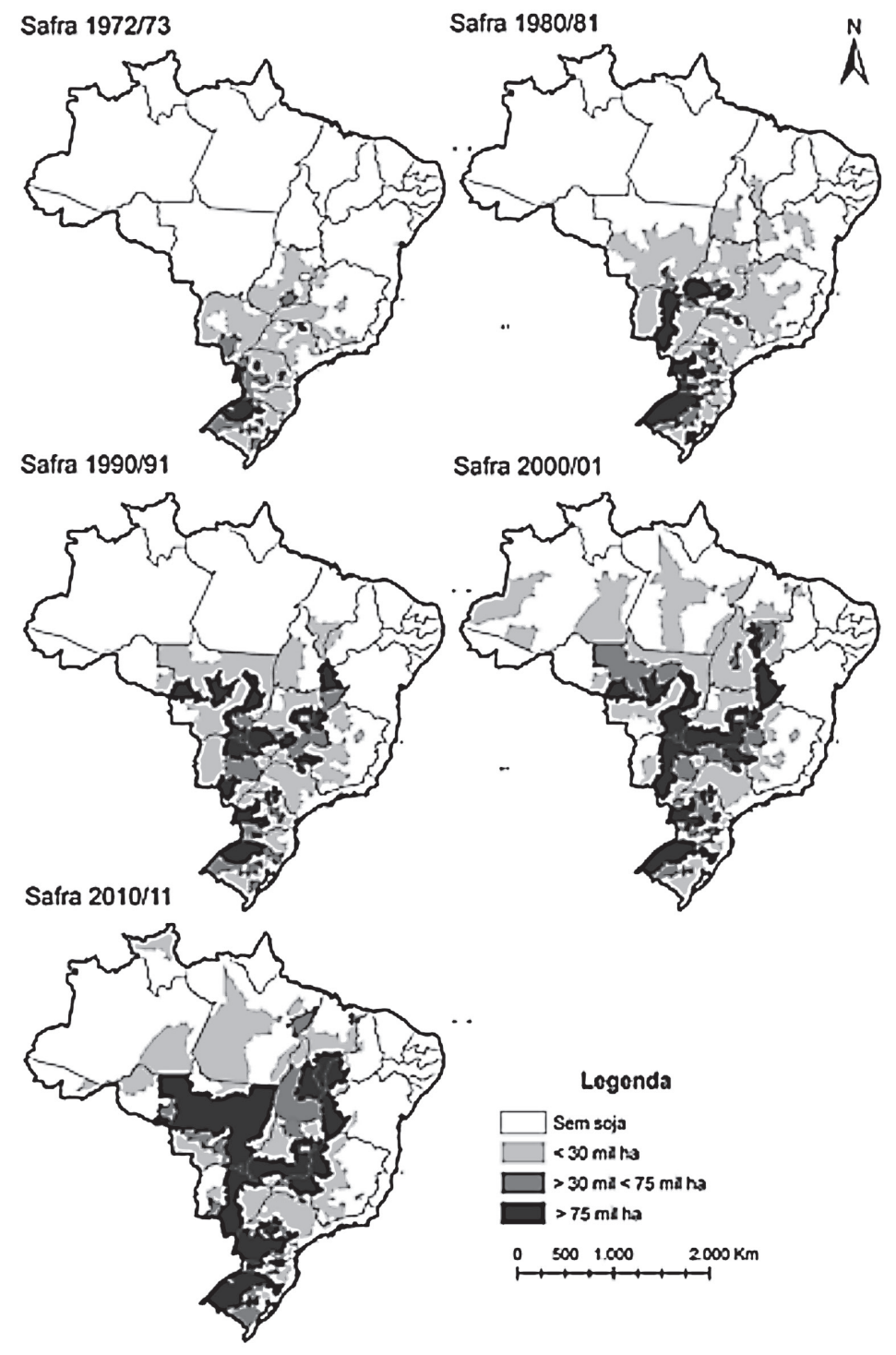

Fonte: Produção Agrícola Municipal (IBGE, 2013). 
O cultivo de soja no Brasil esteve, desde meados de 1960, voltado para a exportação. Ainda que o consumo interno tenha crescido ao longo dos anos, as exportações mantiveram-se majoritárias. Em 2012, $71 \%$ da soja colhida foi enviada ao mercado externo. Apesar desse valor elevado, é pertinente a realização de uma análise mais detalhada, pois ao longo dos anos ocorreram algumas transformações importantes. Uma delas refere-se aos produtos enviados ao exterior, pois $95 \%$ da soja exportada era processada (óleo e farelo) até 1995. Entretanto, a promulgação da Lei Kandir em setembro de 1996 acabou afetando diretamente os bens básicos no Brasil e gerou mudanças significativas no cenário econômico nacional, pela reorientação no formato de acesso ao mercado externo. A Lei Kandir desonerou o Imposto sobre Circulação de Mercadorias e Serviços (ICMS) nas exportações de matérias-primas e manteve o ônus tributário sobre os produtos industrializados. Isso, por um lado, permitiu uma maior competitividade nas exportações das commodities agrícolas brasileiras e, por outro, reduziu sensivelmente a viabilidade da produção agroindustrializada destinada ao mercado externo. Os resultados da Lei Kandir foram imediatos. De 1996 a 1998, a soja exportada em grão passou de 5\% a $30 \%$ (percentual sobre a produção colhida), reduzindo os valores enviados à indústria para produção de óleo e farelo (Wesz Junior, 2011).

A partir de 2000, com o aumento da viabilidade comercial de bens primários no exterior, causado pela desvalorização cambial e pela não isenção tributária para os produtos processados (Lei Kandir), a exportação da soja em grão continuou crescendo, alcançando em 2011 a metade da produção nacional. Em termos absolutos, a quantidade exportada com soja in natura foi ampliada em dez vezes nos últimos quinze anos, passando de 3,5 para 33,8 milhões de toneladas (ABIOVE, 2013). Por outro lado, houve um aumento mais modesto na quantidade de soja destinada ao esmagamento e processamento, visto que ambas as variáveis cresceram em torno de $60 \%$ de 1995 a 2011, enquanto a produção ampliou 250\% para o mesmo período (ABIOVE, 2013; CONAB, 2013).

Outra significativa mudança no destino da soja refere-se ao aumento do consumo doméstico de óleo e à diminuição das exporta- 
ções deste subproduto, tanto em termos relativos (representava $45 \%$ da soja industrializada em 2003 e caiu para 24\% em 2012) quanto absolutos (passou de 2,4 para 1,6 milhão de toneladas no mesmo período). Um dos principais motivos foi a aumento no uso do biodiesel, visto que em 2004 foi criado o Programa Nacional de Produção e Uso do Biodiesel (PNPB), que atualmente determina a mistura obrigatória de 5\% de biodiesel no diesel convencional (Lei n. ${ }^{\circ} 11.097$, de 13 de janeiro de 2005, e Resolução n. ${ }^{\circ}$ 2, de 27 de abril de 2009). O PNPB tem utilizado a soja como principal matéria-prima, e a sua participação sobre o total de oleaginosas esmagadas tem variado entre $77 \%$ e $86 \%$ de 2007 a 2011 (ANP, 2012). Atualmente, segundo a ABIOVE (2013), 27\% do óleo de soja brasileiro é direcionado à produção de biodiesel.

O destino da soja exportada também apresentou importantes mudanças. Enquanto que em 1997 a União Europeia (UE-27) era quem comprava dois terços da soja brasileira (incluindo neste cálculo grão, farelo e óleo), em 2012 esse valor caiu para 30\% do total. Essa redução, em termos relativos, está intimamente relacionada com o aumento das importações chinesas no complexo soja, que beneficiou de forma direta o mercado brasileiro. Em 1997 as exportações para o país asiático representavam apenas 11\% do total, enquanto que em 2012 chegavam a 50\% (MAPA, 2013).

Além do aumento das exportações para a China, ocorreu uma mudança na pauta de produtos enviados ao país asiático. Em 1997, quando o segmento da soja movimentava mais de US\$ 615 milhões, $43 \%$ advinham do farelo, $43 \%$ do óleo e apenas $14 \%$ do grão in natura. De 2000 em diante, a exportação de farelo para a China foi praticamente encerrada, concentrando-se sobretudo no grão. Em 2012, com uma cifra de US\$ 13 bilhões, a soja in natura controlava 93,4\% do valor total do complexo soja. Com este montante, a China tornouse o destino de $70 \%$ das exportações brasileiras de soja in natura, o que caracteriza a grande dependência desse produto em relação a um único comprador (MAPA, 2013; Wilkinson e Wesz Junior, 2013).

Conforme os dados dos Censos Agropecuários, o número de produtores com cultivo de soja de 1975 a 2006 foi reduzido à metade 
- passando de 487 mil para 217 mil. Entretanto, nesse mesmo período, houve um aumento de $216 \%$ na área cultivada e de $430 \%$ na produção, o que evidencia que, ao longo das safras, ocorreu um processo de concentração do cultivo da oleaginosa em um menor número de agricultores. Como poderá ser visto a seguir, tal redução não aconteceu de forma generalizada, isto é, sobre todos os perfis de produtores, mas, sobretudo, naqueles com menores áreas e cuja condição social é de maior vulnerabilidade e instabilidade (parceiros e ocupantes).

Ao analisar os dados dos Censos Agropecuários dos últimos 30 anos (Tabela 1), é possível perceber que o estrato de produtores de soja com menos de 100 hectares de área total apresentou uma brusca redução de 1975 a 2006, principalmente daqueles com menos de dez hectares (de cada quatro agricultores, apenas um manteve-se cultivando a soja). Entretanto, vale destacar que os produtores com área inferior a dez hectares continuam presentes em 2006, respondendo a 18\% do número de estabelecimentos (enquanto que em 1975 alcançavam um terço do total). Em relação à quantidade produzida e à área colhida, a sua participação foi de apenas 1,5\% em 2006. 
Tabela 1 - Número de estabelecimentos produtores de soja, área cultivada e produção por estratos de área total no Brasil (1975, 1985, 1996 e 2006)

\begin{tabular}{|c|c|c|c|c|c|}
\hline \multirow[b]{2}{*}{$\begin{array}{l}\text { Estratos de } \\
\text { área total }\end{array}$} & \multicolumn{5}{|c|}{ Número de estabelecimentos produtores de soja } \\
\hline & 1975 & 1985 & 1996 & 2006 & $\begin{array}{c}\text { Cresc. } \\
1975 / 2006\end{array}$ \\
\hline$<10$ ha & 162.859 & 125.175 & 57.203 & 38.748 & $-76 \%$ \\
\hline$>10<100$ ha & 303.328 & 263.150 & 157.148 & 141.491 & $-53 \%$ \\
\hline $\begin{array}{c}>100<1.000 \\
\text { ha }\end{array}$ & 19.139 & 28.225 & 24.713 & 30.461 & $59 \%$ \\
\hline$>1.000$ ha & 1.543 & 3.537 & 3.927 & 6.080 & $294 \%$ \\
\hline Total & 486.872 & 420.204 & 242.999 & 217.015 & $-55 \%$ \\
\hline \multirow[b]{2}{*}{$\begin{array}{l}\text { Estratos de } \\
\text { área total }\end{array}$} & \multicolumn{5}{|c|}{ Área cultivada com soja } \\
\hline & 1975 & 1985 & 1996 & 2006 & $\begin{array}{c}\text { Cresc. } \\
1975 / 2006\end{array}$ \\
\hline$<10$ ha & 421.533 & 370.324 & 195.068 & 284.318 & $-33 \%$ \\
\hline$>10<100$ ha & 2.772 .522 & 3.293 .734 & 2.328 .920 & 2.813 .942 & $1 \%$ \\
\hline $\begin{array}{c}>100<1.000 \\
\text { ha }\end{array}$ & 1.993 .657 & 3.824 .098 & 3.759 .820 & 6.195 .681 & $211 \%$ \\
\hline$>1.000 \mathrm{ha}$ & 469.015 & 1.943 .310 & 3.195 .987 & 8.588 .353 & $1731 \%$ \\
\hline Total & 5.656 .928 & 9.434 .686 & 9.479 .893 & 17.883 .297 & $216 \%$ \\
\hline
\end{tabular}

\begin{tabular}{c|c|c|c|c|c}
\hline \multirow{2}{*}{$\begin{array}{c}\text { Estratos de } \\
\text { área total }\end{array}$} & 1975 & 1985 & 1996 & 2006 & $\begin{array}{c}\text { Cresc. } \\
\end{array}$ \\
\hline$<10$ ha & 594.016 & 521.844 & 356.726 & 703.345 & $18 \%$ \\
$>10<100$ ha & 4.239 .021 & 5.644 .254 & 5.035 .466 & 6.628 .958 & $56 \%$ \\
$>100<1.000$ & 3.221 .120 & 6.971 .811 & 8.602 .321 & 15.793 .874 & $390 \%$ \\
ha & & & & & \\
$>1.000$ ha & 666.943 & 3.587 .032 & 7.569 .043 & 23.067 .318 & $3359 \%$ \\
\hline Total & 8.721 .274 & 16.730 .087 & 21.563 .768 & 46.195 .842 & $430 \%$ \\
\hline
\end{tabular}

Fonte: Censos Agropecuários de 1975, 1985, 1996 e 2006 (IBGE, 2013).

Por outro lado, houve um aumento, em termos absolutos, no número de produtores cujo estabelecimento possui área total entre 100 e 1.000 hectares. Contudo, o crescimento foi muito mais ex- 
pressivo no estrato com mais de mil hectares, principalmente em termos de área colhida e produção de soja (que foi ampliada em mais de três mil pontos percentuais). Este estrato também apresentou os maiores aumentos relativos no período em análise, passando de $8 \%$ da produção e da área cultivada para aproximadamente 50\% do total. Assim, os dados do Censo Agropecuário de 2006 indicam a grande concentração da soja produzida no Brasil, visto que menos de 3\% dos produtores respondem por $50 \%$ do grão.

Em relação à condição do produtor, é majoritária a presença de sojicultores proprietários, que inclusive ampliaram a sua participação relativa nos últimos anos, dominando mais de $80 \%$ do número de estabelecimentos e da quantidade produzida. Já os parceiros e ocupantes reduziram o seu peso, pois representavam $18 \%$ dos produtores e 7\% da produção em 1975, valores reduzidos para 3,8\% e $1,2 \%$, respectivamente, em 2006. Os arrendatários, por sua vez, têm uma trajetória um pouco diferenciada, uma vez que ampliaram o número de unidades produtoras de soja (passaram de $6 \%$ para $10,6 \%$ ), mas houve uma redução da sua participação na produção a partir de 1985 (caindo de 15\% para 11\%) (IBGE, 2013).

No Brasil, assim como na Argentina, a produção de soja é marcada pela presença de grandes grupos. Em Mato Grosso, principal estado produtor da oleaginosa, os 20 maiores grupos plantaram 533 mil hectares na safra de 2004/05, respondendo a $9 \%$ da área cultivada com a oleaginosa no Estado. Apesar de esses dados apontarem para uma grande concentração, o Instituto Mato-grossense de Economia Agropecuária (IMEA) demonstra que, ao longo dos últimos anos, esses valores foram ampliados, pois na safra de 2009/10 os mesmos 20 grupos já controlavam 1.228 milhão de hectares (crescimento de 318\%), o que representa $20 \%$ da área colhida com soja em Mato Grosso (IMEA, 2010). A concentração também ocorreu, e de forma ainda mais forte, em Mapitoba - acrônimo pelo qual ficou conhecida a região fronteiriça entre os estados do Maranhão, Piauí, Tocantins e Bahia - onde dez grandes companhias controlam uma área superior a um milhão de hectares na região, o que representa cerca de um terço da soja colhida na safra de 2012/13 (Valor Econômico, 2013). 
O nome dos grupos, a área cultivada e a sua nacionalidade são cada vez mais difíceis de identificar diante da presença de grandes empresas de capital aberto, controladas por fundos estrangeiros ou por empresários nacionais ligados a outros ramos da economia. $\mathrm{Na}$ mídia, Bom Futuro, André Maggi, SLC Agrícola e Vanguarda Agro aparecem como os principais grupos nacionais atuantes na produção de soja no Brasil, cada um com pelo menos 140 mil hectares plantados com o grão na safra de 2012/13.

O Grupo Bom Futuro iniciou suas atividades agrícolas em São Miguel do Iguaçu, no Paraná, em 1964, e expandiu para terras mato-grossenses, em 1993, com a compra da primeira fazenda. $\mathrm{Na}$ safra de 2013/14, plantou 560 mil hectares (somando a área plantada na safra e na safrinha), distribuídos em 127 fazendas, divididos em soja (253,4 mil), milho (100 mil), algodão (88,3 mil), milheto (46 mil) e feijão (mil). O Grupo também se envolve com produção de sementes, criação de gado, piscicultura e produção de energia por intermédio de pequenas centrais hidrelétricas (Bom Futuro, 2013; Rally da Safra, 2013). O Grupo André Maggi também iniciou suas atividades no Paraná, em São Miguel do Iguaçu, em 1977, com a produção de sementes e comercialização de safras. A aquisição de terras em Mato Grosso, na década de 1980, permitiu o plantio da soja e a expansão dos negócios. Na safra de 2012/13, foram plantados 141 mil hectares de soja, além de 73 mil de milho e 25 mil de algodão. O Grupo tem investido na verticalização da cadeia produtiva, pois, além das plantações agrícolas, também atua na produção de sementes e fertilizantes, no esmagamento (agroindústrias Amaggi), na comercialização, no transporte fluvial e na produção de energia. Em 2011, o Grupo passou a plantar cinco mil hectares de soja na Argentina (Grupo André Maggi, 2013). Blairo Maggi, sócio e filho do fundador do Grupo, foi governador do Estado de Mato Grosso de 2003 a 2010, sendo em seguida eleito senador. Vale destacar que os principais gestores do Grupo Bom Futuro (Eraí Maggi) e do Grupo André Maggi (Blairo Maggi) são primos.

A SLC Agrícola foi fundada em 1977 pelo Grupo SLC (fabricante de colheitadeiras) e, na safra de 2013/14, possui 14 unidades 
de produção distribuídas em sete estados (RS, MS, MT, GO, BA, MA e PI), que totalizam 340 mil hectares plantados, sendo 185,3 mil de soja, 93,8 mil de algodão, 50,5 mil de milho e 10,7 mil de outros cultivos (café, trigo, milho semente e cana) (SLC Agrícola, 2013). O Grupo Vanguarda Agro, por sua vez, possui 12 unidades de produção localizadas em cinco estados brasileiros (MT, GO, MG, BA e PI), totalizando, sob sua gestão, uma área de aproximadamente 310 mil hectares - 208 mil com plantio de soja em 2012/13 (Vanguarda Agro, 2013). Em suma, os grupos Bom Futuro, André Maggi, SLC Agrícola e Vanguarda Agro controlaram 1,2 milhão de hectares nas últimas safras, dos quais $60 \%$ foram destinados ao cultivo de soja.

Dentre os principais grupos estrangeiros que atuam na produção de soja no Brasil, ganharam destaque nos últimos anos as empresas argentinas El Tejar, Los Grobos, Adecoagro, Calyx Agro e Cresud. Esses cinco grupos, que serão mais bem descritos adiante, controlaram em torno de 700 mil hectares na safra de 2011/12 no Brasil, dos quais a maior parte era destinada à soja. Embora uma das estratégias iniciais fosse o arrendamento das terras, em um segundo momento, esses grupos passaram a investir na compra de áreas. Também estão presentes no cultivo da soja grupos de outros países, com destaque para aqueles com investimentos chineses (Chongqing Grain Group, Pengxin Group etc.) e americanos (Tiba Agro, Teachers Insurance and Annuity Association etc.).

As transformações na cadeia da soja não ocorreram somente entre os produtores do grão, mas também nas empresas que trabalham com a oleaginosa. Dentre os processos evidenciados, merecem destaque a intensificação das fusões e aquisições, a entrada massiva das empresas transnacionais, a concentração empresarial, o aumento da capacidade instalada de esmagamento e a nova regionalização das agroindústrias (deslocando-se do Sul para o Centro-Oeste) (Benetti, 2004; Souza, 2007; Wesz Junior, 2011). Nesse contexto, ganham destaque as empresas transnacionais Bunge, Cargill, ADM e Dreyfus-Coinbra, além da brasileira Amaggi (pertencente ao Grupo André Maggi), que se tornaram as principais firmas do complexo da soja no Brasil. É importante destacar que até 1995 somente a Cargill 
possuía três unidades de esmagamento de soja no Brasil. Após um intenso processo de fusões e aquisições, ADM, Bunge e Dreyfus também passaram a ter controle sobre a propriedade das unidades de beneficiamento do grão, chegando, em 1997, a 20 agroindústrias e, em 2004, (com a presença da Amaggi), a 30 plantas industriais.

Essas empresas avançaram, inicialmente, sobre as principais firmas em funcionamento no mercado nacional (Ceval, Santista, Matosul, Incobrasa, Gessy Lever, Sadia, Sambra, Hering, Hermasa etc.), trocando basicamente a estrutura patrimonial dos empreendimentos. A partir de 1999, quando já haviam consolidado o seu controle sobre uma significativa fatia do mercado, passam a fazer investimentos na ampliação das unidades já existentes e na construção de empreendimentos em novas áreas (sobretudo no Centro-Norte brasileiro). Esta estratégia fez com que Bunge, Cargill, ADM, Dreyfus-Coinbra e Amaggi ampliassem significativamente o seu controle sobre a capacidade instalada de esmagamento da soja (Wesz Junior, 2011).

Como pode ser visto na Figura 3, o controle da capacidade instalada ocorreu de forma rápida e agressiva, principalmente no caso da Bunge, que, em dois anos, passou a controlar $24 \%$ da capacidade de beneficiamento por meio da aquisição de três empresas líderes no Brasil (Ceval, Santista e Incobrasa). Ainda que em um ritmo menos intenso, entre 1997 e 2009, a Cargill praticamente triplicou a sua capacidade de esmagamento, a ADM cresceu $268 \%$ e a Dreyfus manteve-se quase inalterada (Figura 3). Atualmente, as cinco empresas são responsáveis por $50 \%$ do processamento de soja, enquanto que em 1995 esse valor alcançava 6\%.

Além dessa concentração no esmagamento da soja, Bunge, Cargill, ADM, Dreyfus e Amaggi passaram a investir em outras etapas da cadeia produtiva, como produção e venda de insumos, oferta de financiamento, assessoramento técnico, compra do grão, processamento, exportação da soja in natura e venda de mercadorias prontas para o consumo (Farina e Zylbersztajn, 1998; Souza, 2007; Wesz Junior, 2011). Essa estratégia, denominada na literatura como verticalização da produção, tem como característica principal a apropriação das diferentes etapas da cadeia por uma mesma empresa. 
Figura 3 - Capacidade instalada para esmagamento de soja entre 1995 e 2009 no Brasil (t/dia) - Bunge, Cargill, ADM, Dreyfus e Amaggi

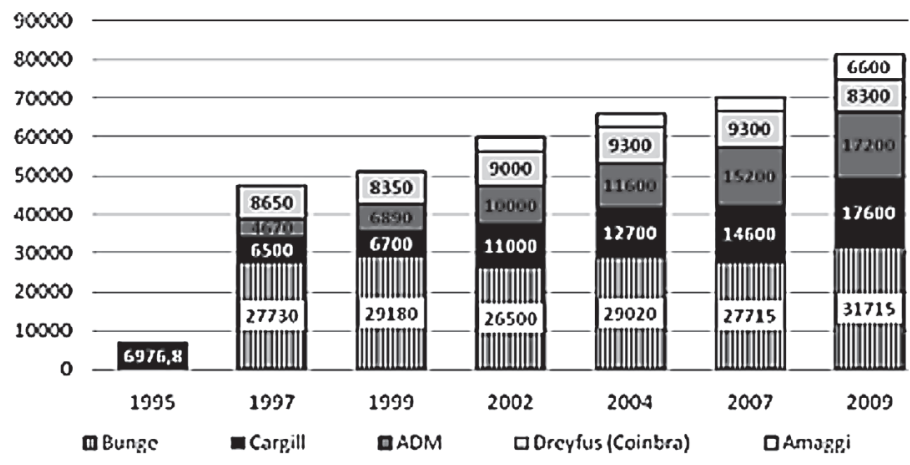

Fonte: Wesz Junior (2011).

A integração vertical tem permitido a elevação da margem de lucro, a redução dos custos produtivos e de transação, a minimização dos riscos e a geração de complementaridades e sinergias entre os diferentes setores (Benetti, 2004; Souza, 2007). Esses resultados se refletem em uma maior e crescente concentração industrial, visto que Bunge, Cargill, ADM, Dreyfus e Amaggi dominavam, em 2010: $50 \%$ da capacidade de esmagamento da oleaginosa, $65 \%$ da produção nacional de fertilizantes, $80 \%$ do volume de financiamento liberado pelas tradings ao cultivo da soja e $85 \%$ do grão comercializado no país (por meio da compra de produtores, grupos familiares, cooperativas e revendas de insumos) (Wesz Junior, 2011).

Ao longo dos últimos anos, o volume exportado por essas cinco empresas cresceu expressivamente no Brasil, passando de 1,8 para 19,3 bilhões (US\$ FOB) entre 1999 e 2012, o que representa 7,5\% das exportações nacionais. Conforme a Figura 4, a Bunge é a empresa com maior peso, superando a faixa dos US\$ 6 bilhões (FOB) em 2012, seguido pela Cargill (4,1 bilhões), ADM (3,8 bilhões), Dreyfus (3,4 bilhões) e Amaggi (1,6 bilhões). Em termos de crescimento, a Cargill e a Dreyfus destacaram-se com um aumento superior a mil pontos percentuais de 1999 a 2012. É importante destacar que, em Mato Grosso, essas empresas dominam as cinco primeiras posições no ranking das maiores firmas exportadoras, controlando, nos últi- 
mos anos, em torno de $60 \%$ das exportações totais do Estado - em 2003 respondiam a menos de 20\% (SECEX, 2013). "A expressividade do Grupo $\mathrm{ABCD}^{4}$ e Amaggi na estabilidade econômica e na geração de superávit na balança comercial do Mato Grosso lhe oferece um importante trunfo para negociar investimentos estatais nas áreas estratégicas das agroindústrias” (Wesz Junior, 2011).

Figura 4 - Valor exportado por Bunge, ADM, Cargill, Dreyfus e Amaggi no Brasil de 1999 a 2012 - em US\$ FOB

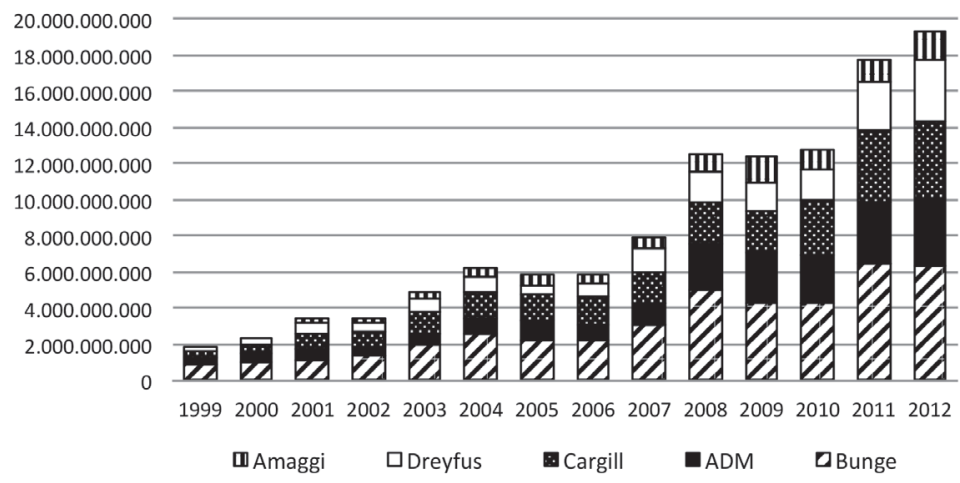

Fonte: SECEX (2013).

Outro ator importante no complexo sojeiro é a cooperativa, responsável pela compra de $35 \%$ do grão produzido no Brasil e por dois terços no Sul do país, segundo informações do Censo Agropecuário de 2006 (IBGE, 2013). Além da compra e armazenagem do grão, muitas cooperativas vendem insumos (sementes, fertilizantes e agroquímicos) em troca da soja a ser colhida, oferecem contratos de compra com preços pré-fixados e algumas ainda esmagam o grão para obter óleo e farelo em indústrias próprias. Em 2012, as cooperativas eram responsáveis por $10 \%$ das exportações de soja in natura e $2 \%$ do óleo (SECEX, 2013). Nos últimos anos, foram criadas novas cooperativas nas áreas de Cerrado, buscando oferecer aos produtores um maior ganho de escala na compra de insumos e na venda da produção.

\footnotetext{
${ }^{4}$ A expressão "Grupo ABCD” refere-se à ADM, Bunge, Cargill e Dreyfus. É importante frisar que muitos autores usam essa denominação por uma facilidade de apresentação. Entretanto, as empresas não atuam conjuntamente e possuem estratégias próprias (complementares e/ou concorrentes) que se diferenciam entre si.
} 


\section{O MERCADO DA SOJA NA ARGENTINA}

Desde o início do século XX, a soja esteve presente na Argentina, ainda que de modo experimental até 1960. Deste período em diante, o grão ampliou a sua área cultivada, passando de mil hectares em 1961 para 30 mil hectares no final da década. Dentre as motivações desse crescimento, estava o início da demanda internacional (a primeira exportação foi em 1961/62), o estímulo de compra por parte das empresas de óleo vegetal, o estabelecimento de um preço mínimo pelo Ministério da Agricultura (MAGyP) e o desenvolvimento de pesquisas genéticas por parte do MAGyP, do INTA (Instituto Nacional de Tecnologia Agropecuária) e de Universidades Nacionais. Entretanto, a produção era muito modesta diante das difíceis condições de manejo (por se tratar de um cultivo novo) e ainda havia concorrência direta do girassol, que detinha maior viabilidade naquele momento. Na década de 60 , a produção do grão localizavase, principalmente, na Província de Misiones, que faz fronteira com o Noroeste gaúcho (região brasileira onde teve início a produção de soja) (Dougnac, 2004; MAGyP, 2013).

As favoráveis condições climáticas e econômicas (principalmente pelos bons preços e pela crescente demanda), além do desenvolvimento genético, consolidaram a soja como cultivo de rotação com o trigo. Essa conjuntura foi chave para que a área plantada e a produção crescessem mais de 50 vezes de 1970/71 até 1979/80, principalmente na região pampiana. De 1980 até a metade dos anos 90, a produção de soja continuou sendo ampliada na Argentina, ainda que houvesse, em determinado momento, uma maior estabilidade - mas nunca uma redução expressiva (Figura 5).

Da safra de 1995/96 em diante, houve um grande crescimento da superfície cultivada com soja na Argentina, que ficou conhecido como "boom de la soja", "sojización”, "oleaginización de la agricultura” e "pampeanización” (Pengue, 2004; Conte et. al., 2009; Guibert et. al., 2011). Na Figura 5, é possível visualizar essa ampliação, com a área sendo triplicada e a produção quadruplicada de 1995/06 até 2010/11. Múltiplos fatores colaboraram para essa forte expansão: 
contexto político-econômico sem regulações, desvalorização cambial após 2001/02, simplicidade no manejo dada a exitosa junção entre plantio direto e OGM, preços internacionais elevados, demanda aquecida, liberalização dos mercados, rentabilidade superior aos outros cultivos, baixo custo financeiro de implantação do cultivo, disponibilidade de variedades adaptadas às distintas condições agroclimáticas, desenvolvimento de novas plantas industriais de esmagamento, investimento em infraestrutura (principalmente portuária), baixo preço das terras no norte do país, alta mobilidade dos produtores e presença de uma cadeia produtiva consolidada (Pengue, 2001; Teubal, 2006; Conte et. al., 2009; Guibert et. al., 2011).

Figura 5 - Área cultivada e produção de soja na Argentina (1970/71 a 2010/11)

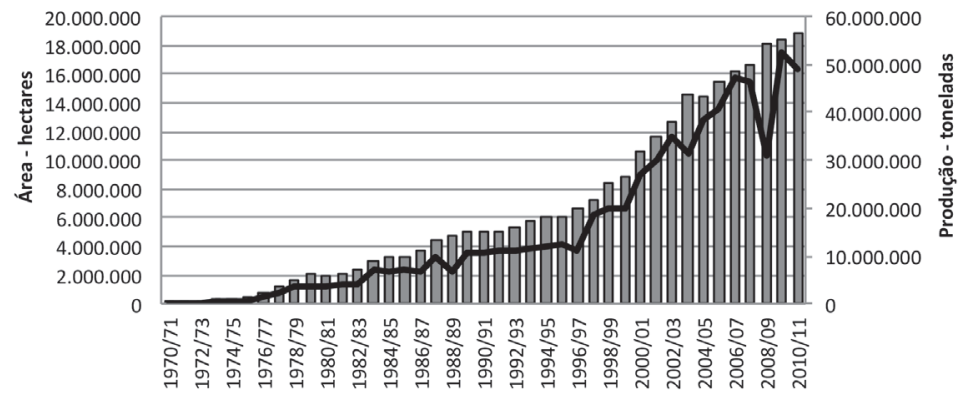

Fonte: MAGyP (2013).

A distribuição espacial da soja também se modificou ao longo dos anos (Figura 6). Embora o grão tenha uma ampla distribuição no território argentino, tem havido intensificação em algumas áreas e ampliação para outras. Durante a década de 1980 e início dos anos 90, a região mais tradicional (províncias de Buenos Aires, Santa Fé e Córdoba) dominava mais de $90 \%$ da área e da produção. Com o "boom de la soja", houve um avanço importante para o Norte do país (principalmente nas províncias de Chaco, Santiago del Estero, Salta, Formosa e Corrientes). Segundo Conte et. al. (2009), essa expansão se deve principalmente ao declínio do algodão, ao baixo preço das terras, a melhorias genéticas, à facilidade de cultivo, à chegada de produtores 
pampianos, à redução dos custos de produção e a avanços tecnológicos. Nos últimos anos, essas novas áreas foram responsáveis por $25 \%$ da superfície cultivada e da soja produzida (MAGyP, 2013).

Essa rápida expansão causou grande impacto nos cultivos concorrentes (milho, sorgo, algodão, girassol, forrageiras etc.) e na pecuária (bovina e ovina), que foram deslocados para outras áreas com o avanço da soja. Em 1980, essa oleaginosa representava apenas $10 \%$ da superfície total cultivada na Argentina, passando a 25\% em 1990, 33\% em 2000 e 63\% em 2009/10 (caso fossem considerados somente os dados dos cultivos de verão e as principais regiões produtoras, os valores seriam ainda maiores). Isso demonstra a velocidade, a intensidade e a dependência que a agricultura argentina passou a ter deste grão, pois, de cada dez hectares plantados no país, seis são de soja (MAGyP, 2013).

Figura 6 - Área cultivada com soja por Departamento na Argentina

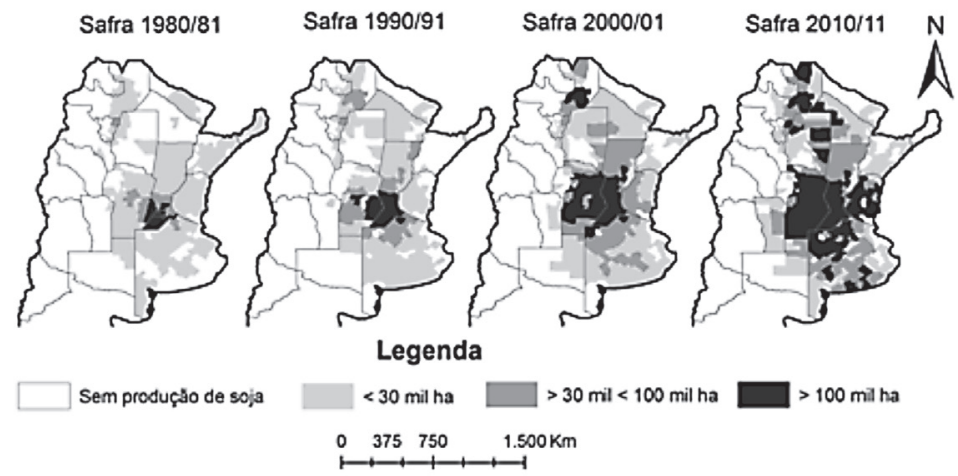

Fonte: MAGyP (2013).

Em paralelo, tem ocorrido uma ampliação da industrialização da soja. Embora o esmagamento tenha crescido um pouco menos que a produção total do grão $(579 \%$ contra $686 \%$, respectivamente, de 1986 a 2010), percebe-se que a diferença é pequena e que o beneficiamento tem, de fato, acompanhado o crescimento da soja na Argentina (CIARA, 2013). Embora, no início da década de 1990, a indústria apresentava certa ociosidade, o aumento da produção foi 
reduzindo a inatividade, bem como estimulando a construção de novas unidades e a ampliação das existentes. Diante disso, o número de unidades chegou a 44, e a capacidade das fábricas cresceu $205 \%$ de 1995 a 2011, atingindo praticamente 175 mil toneladas/dia (Hinrichsen, 2013). Nos últimos anos, entre $70 \%$ e $75 \%$ da oleaginosa é esmagada e transformada em óleo, farelo ou outros subprodutos ${ }^{5}$ (MAGyP, 2013; INDEC, 2013).

O biodiesel de soja também tem ganhado importância no cenário recente, impulsionado principalmente pela Lei Nacional n. ${ }^{\circ}$ 26.093/06, que estabelece a necessidade de o combustível conter, pelo menos, 7\% de biodiesel e/ou bioetanol de 2010 em diante. Essa lei teve vários reflexos sobre a cadeia, como o aumento da demanda de soja, visto que atualmente $27 \%$ do óleo cru é destinado para biodiesel; a instalação de indústrias produtoras, que chegaram a 23 empresas (mas apenas quatro firmas controlam a metade da estrutura de esmagamento); e a ampliação da capacidade de industrialização, que era de 560 mil em 2007 e passou para 3 milhões de toneladas em 2011. Em torno de dois terços do biodiesel é exportado, em grande parte para Espanha, Holanda e Itália (MECON, 2011).

O principal destino da soja é a exportação, enquanto o consumo doméstico absorve, nos últimos anos, em torno de 15\% (MECON, 2011). No mercado interno, a principal demanda é por farelo para alimentação animal, mas, no período recente, ocorreu uma ampliação da demanda por óleo cru para biodiesel e uma manutenção da necessidade de óleo refinado para consumo humano, que é baixa na Argentina. Em termos de valor das exportações, houve um crescimento quase ininterrupto de 1997 a 2011 (a única exceção foi em 2009, quando aconteceu uma grande quebra de safra no país devido às condições climáticas adversas). De 1997 a 2011, o valor exportado do complexo soja cresceu mais de cinco vezes (Figura 7). O farelo sempre respondeu pelo maior montante, oscilando entre $45 \%$ e $55 \%$ do total, seguido pelo óleo, que domina de $20 \%$ a $30 \%$ do valor exportado. Já a soja comercializada in natura foi quem mais cresceu no

${ }^{5}$ Adverte-se que esses dados não podem ser calculados com precisão porque existe uma diferença entre as informações do Ministério de Agricultura, Pecuária e Pesca (MAGyP) e do Instituto Nacional de Estatísticas e Censos da República Argentina (INDEC). 
período analisado em termos absolutos e relativos, passando de 4,5\% em 1997 para mais de 25\% nos anos recentes, em que não ocorreu quebra de safra. Atualmente, a venda em grão supera o valor obtido pelo óleo de soja (INDEC, 2013).

Figura 7 - Valor exportado do complexo soja argentino (em US\$1.000,00) - 1997 a 2011

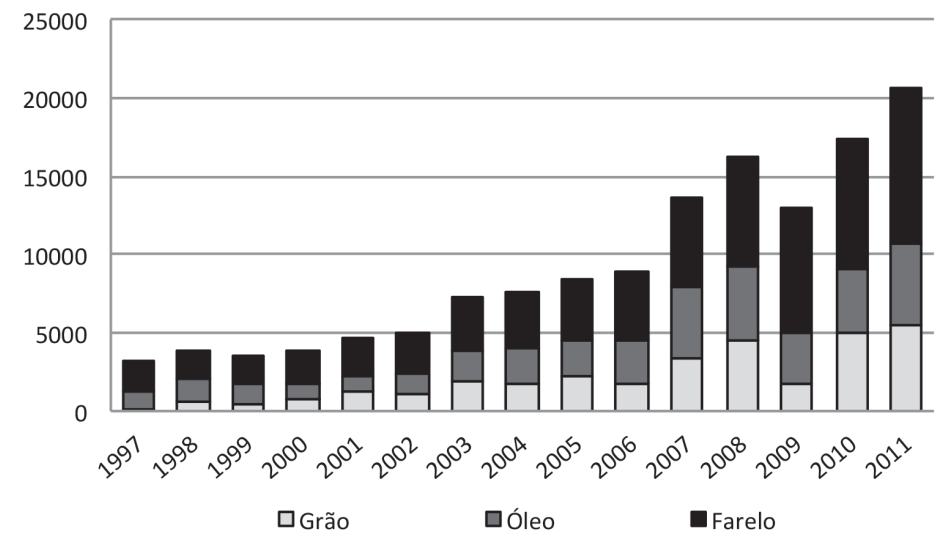

Fonte: INDEC (2013).

O principal destino da soja argentina é a China, que desde 2003 atinge entre $20 \%$ e $30 \%$ do valor exportado, enquanto que em 1993 não chegava a 1\%. O principal produto enviado ao país asiático é a soja em grão, embora também seja comercializado o óleo (mas nos últimos anos tem ocorrido uma redução na quantia comercializada com a China). O segundo principal destino é a Europa, que responde por $22 \%$ do valor total do complexo soja. Neste caso, a demanda é pelo farelo, que representa mais de $90 \%$ das compras do setor, sendo enviado principalmente à Espanha, Itália, Holanda e Polônia. Índia, Iran, Indonésia e África do Sul também são mercados importantes para a soja argentina (INDEC, 2013).

$\mathrm{Na}$ Argentina, havia aproximadamente 50 mil produtores de soja em 2001, dos quais $80 \%$ se concentravam nas províncias de Santa Fé, Buenos Aires e Córdoba (INDEC, 2013). Em 2007, o número de sojicultores cresceu significativamente, alcançando 75 mil (ONCCA, 2008). Ainda que os dados do Censo Nacional Agropecuário 
de 2002 não permitam um aprofundamento sobre as características dos produtores argentinos (e os dados do Censo de 2008 não estejam disponíveis), é possível perceber a concentração da produção da oleaginosa nos grandes estabelecimentos (Figura 8). As unidades menores que 50 hectares, ainda que concentrassem 13\% dos produtores de soja, em termos de área representavam apenas $1 \%$. No outro extremo, estão os estabelecimentos com mais de mil hectares, que respondiam por $12 \%$ dos produtores e pela metade da superfície cultivada (em algumas províncias, como La Pampa, San Luis e Corrientes, esse valor chegava a mais de $60 \%$ ).

Figura 8-Produtores de soja e área cultivada por estratos de área total na $\operatorname{Argentina}^{6}$ (2002)

\section{Produtores}

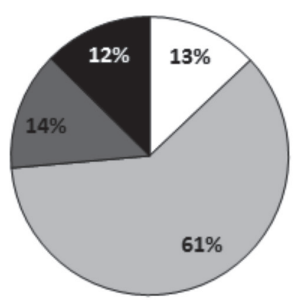

Fonte: INDEC (2013).

\section{Área cultivada}

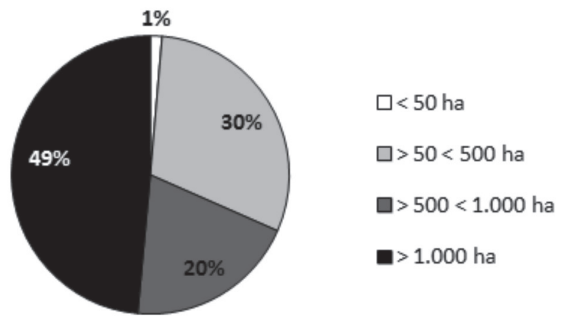

Apesar de o gráfico exposto indicar uma elevada concentração da soja nos produtores com mais de mil hectares, Genok (2012) aponta que esse processo é ainda mais intenso no período atual. Segundo o autor, 50\% da produção de soja na Argentina em 2010 é controlada por $2,6 \%$ dos produtores, que detêm estabelecimentos com mais de cinco mil hectares. Essas informações colaboram com o argumento de que o modelo "bem-sucedido" da soja está concentrado em um reduzido número de grandes produtores, pois a maioria dos pequenos e médios não é capaz de obter investimento necessário para realizar a produção de modo competitivo, além de muitos agricultores serem expulsos de suas terras - particularmente ocupantes e indígenas (Teubal, 2006).

\footnotetext{
${ }^{6} \mathrm{~A}$ área cultivada foi calculada a partir dos dados de todas as províncias argentinas. Entretanto, para o número de produtores, os dados disponíveis referem-se às províncias de Buenos Aires, Córdoba, Entre Rios, La Pampa, San Luis e Santa Fé, que representam 87,4\% da área de soja do país. Nas demais regiões, onde o cultivo é mais recente, não havia informações para essa variável.
} 
Para Teubal (2006), a redução de $20 \%$ no número de estabelecimentos agropecuários de 1988 a 2002 (que atingiu principalmente os pequenos e médios, enquanto os grandes cresceram) deve-se, em parte, a essa dinâmica da soja. Grosso et. al. (2010) compartilham esta percepção e afirmam, a partir dos dados preliminares do Censo Nacional Agropecuário de 2008, que o desaparecimento dos estabelecimentos menores foi ainda mais intenso entre 2002 e 2008.

Grosso et. al. (2010) argumentam que, apesar da presença desses diferentes tipos de produtores (grandes proprietários, agricultores familiares capitalizados, empresários agrícolas etc.), são os grandes grupos que têm ganhado mais atenção nos trabalhos acadêmicos no período atual visto a sua forte expansão, seja na Argentina ou em outros países. Os principais grupos são: El Tejar, Los Grobos, Adecoagro, MSU, Cresud e Calyx Agro. Estas firmas, em 2008, integravam um grupo de 15 empresas, que juntas controlavam um total de três milhões de hectares na Argentina, o que correspondia a 18\% do total plantado com soja (Oyhantçabal e Narbondo, 2011).

El Tejar foi fundado em 1987, na província de Buenos Aires, com o foco na pecuária bovina, mas em princípio dos anos 90 passou a dedicar-se também à agricultura. Atualmente, é um dos maiores produtores de grãos do mundo. Na Argentina, já chegou a possuir mais de 300 mil hectares de área plantada, mas a superfície vem se reduzindo diante do aumento dos preços da terra arrendada. "Na província de Santa Fé, por exemplo, o preço do aluguel pulou de US\$ 150 em 2001 para US\$ 650 no ano passado [2012]” (La Nación, 2013). Em 2007, El Tejar vendeu 23,5\% das suas ações para o fundo de investimento anglo-americano Altima Partners por US\$ $50 \mathrm{mi}-$ lhões, utilizando os recursos para comprar terras pela primeira vez. The Capital Group investiu US\$ 150 milhões na empresa e passou a controlar 13\% das suas ações. Também recebeu um crédito de US\$ 150 milhões do banco holandês FMO, destinado a comprar terras no Brasil (Oyhantçabal e Narbondo, 2011). Na safra de 2011/12, El Tejar produzia soja na Argentina, no Brasil, no Uruguai e na Bolívia, sendo 70\% em áreas arrendadas (Infocampo, 2013).

Los Grobos foi criada em 1984, mas a trajetória da família 
de origem russa nas terras argentinas começou no início do século XX. Ao longo das décadas, foram expandindo os seus negócios e, atualmente, não se envolvem apenas com o cultivo de grãos, mas também com a produção de sementes e a fabricação de agroquímicos, além de oferecer logística, financiamento, ferramentas de gestão e de risco, armazenagem e industrialização. Em paralelo, a empresa mantém uma rede de 1.800 pequenas e médias empresas provedoras de serviços (transportes, plantio, pulverização, colheita, laboratórios etc.) (Grosso et. al., 2010). Los Grobos cultiva 120 mil hectares de soja na Argentina, além das áreas de produção no Brasil, Uruguai e Paraguai (grande parte das terras é arrendada). O faturamento total da empresa foi de US\$ 1 bilhão em 2011/12, enquanto que em 2001/02 esse valor era de US\$ 57 milhões (ampliação das receitas em 17 vezes em dez anos) (Bell e Scott, 2010; Los Grobos, 2012). Conforme Oyhantçabal e Narbondo (2011), a empresa dispunha de US\$ 250 milhões, via Pactual Capital Partners e Touradji, para comprar terras no Brasil.

Adecoagro é uma empresa argentina capitalizada pelo milionário húngaro-americano George Soros. Em 2002, ano de sua criação, comprou 74 mil hectares no pampa úmido argentino. Ao longo dos anos, foi expandindo suas áreas próprias e, atualmente, possui 270 mil hectares na Argentina, no Brasil e no Uruguai, além das terras arrendadas (Adecoagro, 2013). As suas atividades incluem a produção de cereais, oleaginosas, lácteos, açúcar, etanol, café e algodão. Adecoagro diferencia-se dos dois grupos citados anteriormente, principalmente porque grande parte das suas terras é própria e o seu portfólio de atividades é mais amplo. Segundo Oyhantçabal e Narbondo (2011), a empresa abriu o seu capital em 2011 e começou a operar na Bolsa de Valores de Nova Iorque, em que arrecadou US\$ 314 milhões, dos quais destinaria US\$ 150 milhões para compra de terras na Argentina, no Brasil e no Uruguai.

MSU (Manuel Santos de Uribelarrea) iniciou suas atividades em 1986, com a produção de 15 mil hectares de agricultura e 6.500 cabeças de gado em terras próprias nas províncias de Santa Fé e Buenos Aires. Atualmente, possui 120 mil hectares na Argentina e trabalha com mais de cem empresas contratistas, que terceirizam plantio, 
pulverização, colheita, comercialização e auditoria. Oyhantçabal e Narbondo (2011) afirmam que MSU está conformando o fundo Santa Joana Ltda de até US\$ 500 milhões para comprar terras no Uruguai, Paraguai e Brasil, onde já desenvolve a atividade agropecuária.

Dentre os grupos citados, a Cresud é quem detém o maior controle fundiário, com 628 mil hectares na Argentina, mas também atua no Brasil, no Paraguai e na Bolívia. A empresa pertence ao grupo IRSA da família Elsztain e dedica-se à produção agrícola, de carne e de leite. Em 1994, tinha 20 mil hectares e passou a comprar mais áreas com fundos de George Soros, que, em 2001, saiu dessa empresa para atuar na Adecoagro. Elsztain normalmente financia a expansão da Cresud por meio de vendas de ações na Nasdaq, em que opera desde 1997. Em junho de 2011, foi assinado um contrato para uma joint venture com a maior empresa agrícola da China, Heilongjiang Beidahuang Nongken Group, para comprar terras e soja na Argentina (Farm Land Grab, 2011).

Além dessa concentração na etapa de produção, vários autores (Pierri, 2006; Teubal, 2006; Schavarzer e Tavosnanska, 2007; INTA, 2009; Lavarello, Gutman e Rios, 2010) destacam que o setor de industrialização da soja também está dominado por um pequeno número de grandes empresas. Em 2010, apenas oito firmas controlavam $80 \%$ da capacidade instalada e grande parte das exportações do segmento ( $90 \%$ do óleo, $85 \%$ do farelo e $84 \%$ do grão in natura). Grosso modo, as empresas diferenciam-se entre nacionais e transnacionais. No primeiro grupo, destacam-se Aceitera General Deheza (AGD), Molinos Rio de la Plata e Vicentin, que possuem indústrias de produção de óleo, farelo e biodiesel, além de armazéns e terminais portuários para exportação. A capacidade de esmagamento dessas três empresas chega a $39 \mathrm{mil} \mathrm{t} / \mathrm{dia}$ em 2011, o que corresponde a $22,7 \%$ dos valores nacionais (até o início da década de 2000, superavam os 30\%) (Hinrichsen, 2013). Apesar desse resultado, AGD, Molinos e Vicentin detêm uma participação maior nas exportações de óleo e farelo em 2010, pois alcançam 33\% e 37\%, respectivamente (nos últimos anos, essas empresas praticamente não exportaram soja in natura).

Dentre as empresas transnacionais, destacam-se Cargill, 
Bunge, Dreyfus, ADM, Noble e Nidera. Ao longo dos últimos 15 anos, com o processo de liberalização econômica, essas firmas ampliaram o seu poder no mercado argentino, com investimentos em infraestrutura - controlam $58 \%$ da capacidade de industrialização em 2011 (Figura 9) - e crescimento expressivo nas vendas para o mercado exterior - respondem por $22 \%$ das exportações totais na Argentina em 2011. No segmento da soja, são responsáveis por $85 \%$ das exportações in natura, $70 \%$ do óleo e $54 \%$ do farelo (Hinrichsen, 2013; MAGyP, 2013). É importante destacar, ainda, que apenas a Nidera não está envolvida na produção de biodiesel.

Figura 9 - Capacidade instalada das empresas transnacionais esmagadoras de soja na Argentina (1997 - 2011)

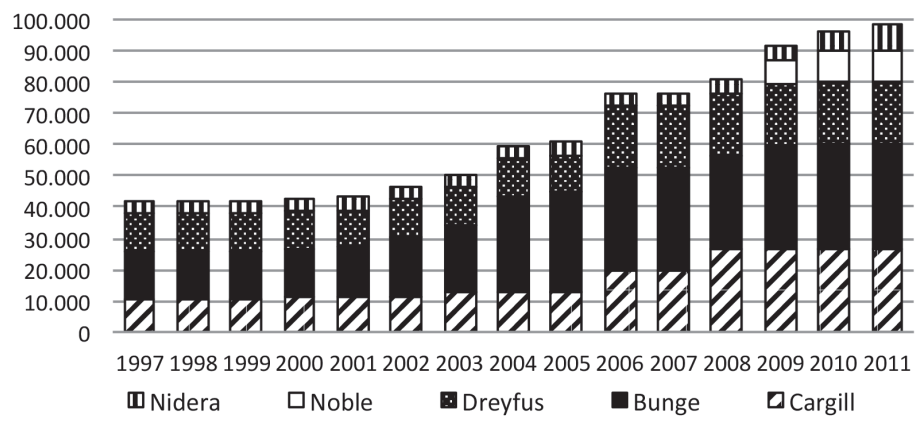

Fonte: Hinrichsen (2013).

Para Pierri (2008), essa expansão das grandes empresas transnacionais tem reduzido a participação das cooperativas, que, até meados da década de 1990, assumiam maior destaque e importância. Em 1980, as cooperativas respondiam por $20 \%$ do total exportado com subprodutos da soja, caindo para 8,8\% em 1996. Apesar de muitas cooperativas terem falido ao longo das últimas duas décadas, a Asociación de Cooperativas Agrarias (ACA) tem se mantido e é considerada a mais importante na Argentina. As exportações de óleo e farelo da ACA apresentaram uma redução significativa entre 1988 e 2010, visto que, no período precedente, o primeiro produto representava $16,6 \%$ do total nacional e o segundo $4,2 \%$ (enquanto que, atualmente, ambos encontram-se abaixo de $2,5 \%$ ). Nas expor- 
tações de soja in natura, ocorre um processo diferenciado, com uma retomada da sua representatividade (passou de 4\% em 2000 para $10 \%$ em 2010). Nos últimos anos, a ACA tem figurado entre as vinte maiores exportadoras em termos de valor, com um montante de US\$ 766 milhões em 2011 (INDEC, 2013).

\section{DINÂMICAS, PROCESSOS E ATORES NO MERCADO DA SOJA NO BRASIL E NA ARGENTINA}

A expansão da soja ocorreu de modo intenso ao longo dos últimos anos no Brasil e na Argentina. O chamado "boom da soja" teve início por volta da metade da década de 1990, sendo caracterizado, principalmente, pela elevada taxa de crescimento da área cultivada. De um modo geral, essa ampliação segue até o período atual, com destaque ao caso argentino, onde a superfície plantada apresentou um aumento ininterrupto ao longo dos últimos 15 anos. Muitos elementos contribuíram para essa dinamização do grão na região, como os fatores externos (internacionais) e internos (domésticos).

Dentre os principais fatores externos responsáveis pela ampliação da área de soja, destacam-se: aumento do preço em determinado períodos, quebra de safra em alguns países produtores, redução dos estoques mundiais, estímulo à produção e ao consumo de energias renováveis, acordos comerciais entre os países (garantindo a compra do grão) e crescimento da demanda mundial da soja e de seus derivados, alavancado em especial pela China e pelas outras nações asiáticas ${ }^{7}$. Dentre os impulsos nacionais, há uma série de programas e instrumentos de intervenção presente nos diferentes países, que podem ser agrupados em ações setoriais (políticas de crédito rural, de preços, fundiárias e de ordenamento territorial, pesquisas agronômicas, assistência técnica etc.) e não setoriais (políticas trabalhistas, ambientais, industriais, comerciais, fiscais, cambiais, tributárias, migratórias, energéticas, de infraestruturas e serviços etc.).

Entretanto, os impulsos domésticos não podem ser analisados como ações pontuais ou desconectadas, mas como um conjunto de ins${ }^{7}$ É pertinente apontar que também houve um crescimento da demanda interna no Brasil e na Argentina, inicialmente, para alimentação humana e animal e, no período mais recente, para a produção de biodiesel. 
trumentos mobilizados para sustentar um modelo de desenvolvimento agroexportador, que, ao longo dos anos, foi se modificando e reestruturando a partir do contexto político-econômico nacional e internacional. É impressionante como esse modelo de política econômica pautado no desenvolvimento agroexportador - que fora destacado por Censo Furtado nas décadas de 50 e 60 , que se orienta pela demanda internacional (principalmente dos países industrializados, mas não só) e que se mantém como provedor de matéria-prima - permanece vigente no momento atual, apesar de algumas adaptações ao contexto contemporâneo.

Além dos elementos pontuados, Guibert et. al (2011) destacam que foi imprescindível para o boom da soja as transformações tecnológicas e sócio-organizacionais. Quanto às mudanças técnicas, os autores chamam atenção para a grande importância que teve a introdução do plantio direto e de variedades transgênicas, que simplificaram o cultivo e o manejo, reduziram os custos de implementação e aumentaram a produtividade e a rentabilidade. No campo sócio-organizacional, foram as facilidades de informação e comunicação, a gestão empresarial, as novas ferramentas financeiras e a organização das empresas em redes de negócios que permitiram a introdução de fontes financeiras de outros setores, a ampliação da mobilidade dos atores e o controle de um maior volume de áreas em diferentes regiões.

Além de a soja ser o principal cultivo nos dois países e ter apresentando uma grande expansão em termos de área e produção, outras semelhanças podem ser destacadas. Uma delas refere-se ao cultivo em estabelecimentos com grandes extensões de terra, processo que tem intensificado nos últimos anos, fazendo com que um menor número de produtores maneje superfícies cada vez mais amplas de soja. Conforme a Figura 10, as unidades com área total superior a mil hectares têm uma participação pequena no número de estabelecimentos produtores do grão, mas controlam $48 \%$ da superfície cultivada em ambos os países. Dentre os fatores que favorecem essa crescente concentração da soja nos grandes produtores, cabe destacar a própria dinâmica da cadeia produtiva, visto que se trata de um cultivo com baixa diferenciação do produto final, sendo fundamental o ganho de escala e a negociação de grandes volumes para reduzir os custos e ampliar 
a rentabilidade. Por outro lado, os médios e grandes estabelecimentos foram, historicamente, os maiores beneficiados pelas políticas públicas para o setor nos diferentes países, o que potencializa ainda mais a sua supremacia sobre os demais estratos de produtores.

Figura 10 - Número de estabelecimentos produtores e área cultivada com soja por estratos de área total no Brasil e na Argentina ${ }^{8}$

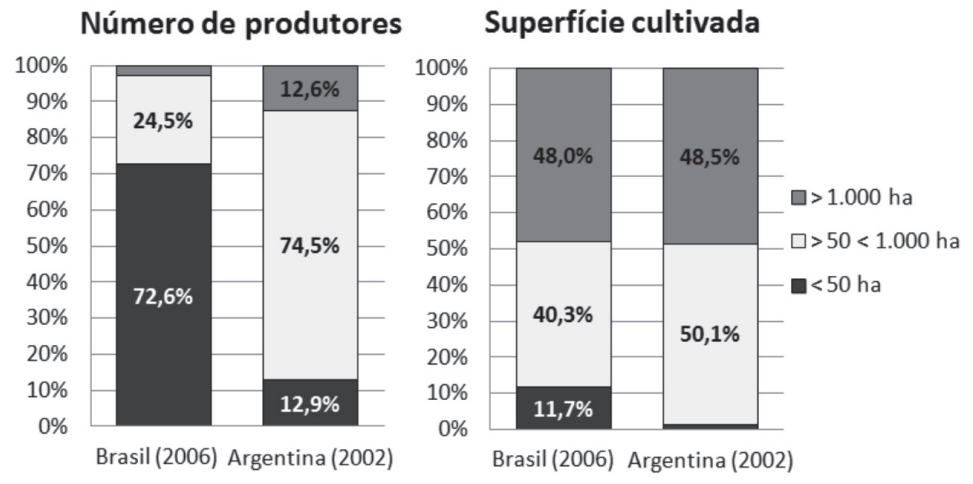

Fonte: IBGE (2013) e INDEC (2013).

Os agricultores com menores dimensões territoriais (unidades com área total inferior a 50 hectares) mantêm-se majoritários no número de produtores de soja no Brasil (72,6\%), enquanto que na Argentina esse valor chega a $13 \%$. A presença da agricultura familiar e dos assentados da reforma agrária no cultivo do grão no Brasil pode estar vinculada às políticas públicas para esse público, como o Programa Nacional de Fortalecimento da Agricultura Familiar (Pronaf), Mais Alimentos, Programa Nacional de Produção e Uso do Biodiesel (PNPB), Seguro da Agricultura Familiar (SEAF), Programa de Garantia de Preço da Agricultura Familiar (PGPAF), Programa Garantia Safra etc. Tais políticas públicas, ao oferecem para a agricultura familiar crédito de custeio e investimento, pagamento diferenciado pelo produto, proteção às variações nos preços e

\footnotetext{
${ }^{8}$ Para a construção desta Figura, não foi possível utilizar dados padronizados oriundos de uma mesma fonte, o que significa que pode haver diferenças no conceito da unidade de referência (exploração agropecuária e estabelecimento agropecuário) entre os dois países. Além disso, os dados não correspondem ao mesmo ano de referência e foram usados apenas três extratos de área (menos de 50 hectares, de 50 a 1.000 hectares e acima de 1.000 hectares) para obter a comparabilidade.
} 
seguro em caso de intempéries climáticas, estimulam o cultivo de soja e a especialização produtiva, integrando cada vez mais os agricultores familiares às demandas da indústria e às relações de mercado (Grisa e Wesz Junior, 2010; Leite, Delgado e Wesz Junior, 2010; Mattei, 2011).

Como os dados da Figura 10 não estão atualizados, acreditase que a concentração da produção tenha se intensificado ainda mais nos últimos anos, visto o crescimento dos grandes grupos produtores de grão no período recente. Não se trata, entretanto, de grupos homogêneos, sendo possível diferenciar, pelo menos, dois grandes perfis: "modelo tradicional" e "modelo argentino". O primeiro tem como principais características: propriedade da terra (ainda que áreas complementares sejam arrendadas), trajetória familiar na agricultura, atuação em atividades complementares (produção de sementes, armazenagem, transporte etc.), gestão combinada (familiar e profissional), forte adaptabilidade às novidades tecnológicas, existência de capital fixo (maquinários, equipamentos e infraestrutura - silos, armazéns etc.) e articulação com empresas provedoras de insumos, financiamento e compra do grão. Estes produtores têm modernizado suas estratégias financeiras e produtivas nos últimos anos, mas seguem operando na dualidade "propriedade da terra" e "desenvolvimento da produção" (Gras, 2012). Os grupos com esse perfil são majoritários no Brasil.

O segundo perfil dos grandes grupos surgiu e consolidouse na Argentina e apresenta diferenças importantes em relação ao primeiro, tais como: controle de grandes superfícies de terras sem um "enraizamento geográfico"; atuação supranacional; ausência de origem rural (ainda que muitas vezes haja um vínculo setorial); existência quase nula de capital fixo (geralmente não são proprietários das terras e das máquinas), arrendando grandes extensões de terras (embora nos últimos anos tenham investido na compra a partir de fundos de investimentos); organização em redes de negócios para contratação de equipes de plantio, pulverização, colheita e transporte; gestão financeira, econômica, comercial e agronômica bastante profissional (incluindo a utilização de seguros contra eventos climáticos); sistema de produção agrária dinamizado pela presença de 
capitais externos ao empreendimento (capital financeiro); comercialização dos produtos realizada em mercado de futuros e exportação, em alguns casos, feita pela própria empresa; compra de insumos em grandes volumes, com importação direta (Arbeletche e Carballo, 2006; Grosso et. al., 2010; Guibert et. al., 2011; Gras, 2012). Esse segundo "modelo" tem crescido de forma intensa nos últimos dez anos, espraiando-se para todos os países do Cone Sul. Os principais grupos são El Tejar, Los Grobos, Adecoagro, MSU e Cresud, que controlavam na safra de 2011/12 mais 2,5 milhões de hectares no Brasil, na Argentina, no Paraguai, na Bolívia e no Uruguai, cuja maior parte das áreas é destinada ao cultivo da soja. Cada grupo atua de forma paralela em pelo menos três países e possui uma superfície mínima de 250 mil hectares por firma. Esses atores são exemplo do processo correlato de concentração e desterritorialização da riqueza nas atividades agropecuárias.

Esses dois "modelos" descritos sintetizam, em parte, os distintos modos de produção e de gestão predominante no Brasil e na Argentina. No caso argentino, o Censo Agropecuário não permite um detalhamento dos dados, mas vários estudos apontam que grande parte da soja é cultivada em áreas arrendadas (estima-se que dois terços da superfície agrícola do país se encontrem em regime de arrendamento) e que as formas de organização do processo produtivo estão baseadas na terceirização das tarefas (em algumas regiões, $90 \%$ da colheita é realizada por prestadores de serviços). Portanto, é baixa a existência de capital fixo, pois os produtores geralmente não são proprietários das terras e das máquinas. Em relação aos recursos investidos para o plantio da soja, é predominante o uso do capital financeiro, principalmente pelos grandes produtores. Além disso, geralmente os sojicultores não vivem na propriedade ou na área que arrendam (moram em cidades médias ou grandes próximas), possuem um elevado nível de instrução (sendo, sobretudo administradores, economistas e/ou agrônomos) e são relativamente jovens (Grosso et. al., 2010; Guibert et. al., 2011; Reboratti, 2010; Gras, 2013).

No Brasil, os dados do Censo Agropecuário de 2006 permitem uma análise aprofundada dos modos de produção da soja, bem como do 
perfil dos produtores desse grão. A partir dessa base, fica evidente que no Brasil a soja é produzida principalmente em terras próprias (estimase que o arrendamento ocupe apenas $16 \%$ da área) e que os recursos para custear a atividade advêm do crédito rural, visto que $61 \%$ dos produtores de soja acessam financiamento, o qual, em $86 \%$ dos casos, é feito por intermédio dos bancos. Outro elemento que difere é a terceirização das tarefas, já que no Brasil apenas 10\% dos sojicultores afirmaram que realizam a contratação de serviços, valor que corresponde a $0,4 \%$ das despesas totais do estabelecimento. A maioria dos produtores (com exceção de parte dos estabelecimentos familiares, que detém menor poder econômico) possui máquinas próprias, como tratores, grades, plantadeiras, colheitadeiras, pulverizadores etc. - em 2006, $81 \%$ do valor dos investimentos foram com a compra de máquinas e benfeitorias. Em relação ao perfil dos produtores que cultivam a oleaginosa, a maior parte é formada por gestores que estão a mais de 10 anos na direção do estabelecimento (71\%), que tem mais de 40 anos (78\%) e baixa escolaridade ( $77 \%$ tem até o ensino fundamental) e que moram no próprio município onde se localiza o estabelecimento (92,5\%) - a grande maioria reside no próprio estabelecimento (IBGE, 2013). A partir dessas informações, fica clara a diferença em relação à situação argentina, demonstrando dois distintos modelos de produção, ainda que o elevado padrão tecnológico da produção seja comum em ambos os países.

Quanto às empresas envolvidas na compra do grão, Bunge, Cargill, ADM e Dreyfus estão presentes nos dois países. Apesar de iniciarem suas atividades em períodos diversos, foi nos últimos vinte anos, durante a abertura econômica, liberalização comercial e globalização dos mercados, que passaram a assumir grande protagonismo no setor. Até 1995, apenas Cargill e Dreyfus tinham instalado planta industrial no Brasil e na Argentina, com um controle inferior a $10 \%$ da capacidade instalada de esmagamento (Figura 11). Dessa data em diante, outras empresas, como Bunge e ADM, passaram a investir nesses países. Uma estratégia inicial, comum para ambas as empresas, foi a realização de fusões e aquisições, quando avançaram sobre as principais firmas em funcionamento no mercado nacional, trocando basicamente a estrutura patrimonial dos empreendimentos. 
Após consolidarem o seu controle sobre uma significativa fatia de mercado, passam a efetuar investimentos na ampliação das unidades já existentes e na construção de empreendimentos em novas áreas (Pierri, 2008; Wesz Junior, 2011).

Em 2002, já é possível visualizar o reflexo das fusões e aquisições, quando Bunge, Cargill, ADM e Dreyfus passaram a dominar $50 \%$ da capacidade instalada de esmagamento, com um controle de quase $100 \mathrm{mil}$ toneladas/dia. Esse processo ocorreu de forma rápida e agressiva, visto que, em 1995, havia apenas duas empresas que controlavam 9\% da capacidade (16 mil t/dia). A Bunge, em pouco tempo, tornou-se a maior empresa, controlando $23 \%$ da capacidade de beneficiamento nos dois países em 2002 (Figura 11). Apesar de o Grupo ABCD ampliar, em termos absolutos, a sua capacidade instalada ao longo dos últimos anos, chegando a $165 \mathrm{mil}$ t/dia em 2011, o percentual de controle do setor mantém-se no mesmo patamar de 2002 (em torno de 50\%). Em 2011, Bunge mantém a liderança na capacidade de esmagamento (65 mil t/dia), seguida pela Cargill (44 mil t/dia), Dreyfus (28.300 t/dia) e ADM (17 mil t/dia) (Figura 11).

Figura 11 - Capacidade instalada para esmagamento de soja pelo Grupo ABCD em 1995. 2002 e 2011. no Brasil e na Argentina (toneladas/dia)

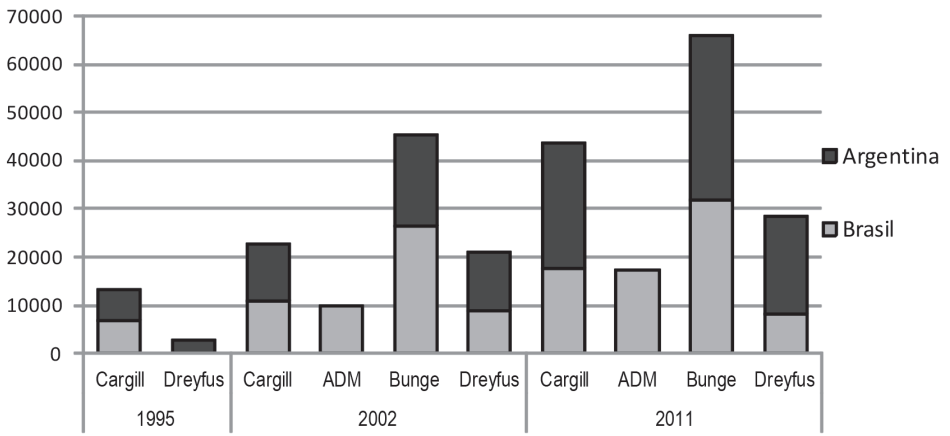

Fonte: Wesz Junior (2011), Hinrichsen (2013), sites das empresas e documentos midiáticos.

Além dessa concentração no esmagamento da soja, Bunge, Cargill, ADM e Dreyfus passaram a investir em outras etapas da cadeia produtiva, como produção e venda de fertilizantes, oferta de 
financiamento, assessoramento técnico, compra do grão, industrialização, exportação e vendas no mercado doméstico (Pierri, 2006; Souza, 2007; Wesz Junior, 2011). Essa estratégia de verticalização da produção foi fundamental para a ampliação no valor das exportações no Brasil e na Argentina, onde são líderes no complexo soja. De 2005 a 2011, a venda das empresas ao exterior passou de US\$11,7 para US\$ 30,7 bilhões FOB (crescimento de 163\%), enquanto que o restante das exportações teve uma ampliação em um ritmo menor (106\%). Como pode ser visto na Figura 12, de 2005 a 2007, houve um aumento importante nas exportações das firmas, mas a queda nos preços internacionais da soja reduziu o valor em 2008, que voltou a crescer nos anos consecutivos. Ainda que a ADM e a Dreyfus tenham apresentado um ritmo de crescimento maior das exportações, superando os $200 \%$ entre 2005 e 2011, é a Bunge e a Cargill que dominam quase dois terços das exportações totais do Grupo ABCD (Figura 12).

A participação que Bunge, Cargill, ADM e Dreyfus exercem sobre o valor das exportações totais dos dois países cresceu significativamente ao longo dos anos, passando de 7,4\% em 2006 para $9,4 \%$ em 2011. Tal informação demonstra o elevado poder comercial e econômico que as empresas transnacionais detêm nos países em análise, que não se limita apenas ao campo setorial (complexo soja), pois, como a soja é o principal produto das exportações, essas firmas figuram entre as primeiras exportadoras a nível geral.

Figura 12 - Exportações totais do Grupo ABCD no Brasil e na Argentina (em US\$ FOB) -2005 a 2011

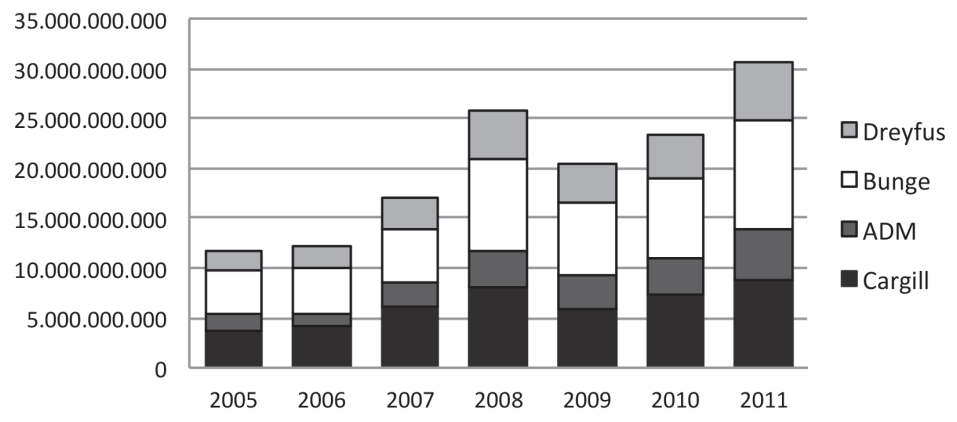

Fonte: SECEX (2013), INDEC (2013) e COMEX (2013). 
Apesar de as exportações de óleo e farelo de soja serem importantes para as empresas transnacionais, a venda in natura tem ganhado muita atenção nos últimos anos, em especial após a crescente demanda da China pelo produto em grão. Atualmente, estimase que Bunge, Cargill, ADM e Dreyfus controlem entre $70 \%$ e $80 \%$ das exportações de soja in natura no Brasil e na Argentina (Wesz Junior, 2011; INDEC, 2013; COMEX, 2013). Essa tem sido, de fato, uma das principais estratégias das empresas nos últimos anos, que é potencializada, no caso brasileiro, pelo marco regulatório (Lei Kandir). Esse contexto mais atrativo às exportações in natura ajuda a entender a manutenção, em termos relativos, do controle do Grupo ABCD sobre a capacidade de esmagamento - que permanece próxima de $50 \%$ nos últimos dez anos - enquanto que na última virada do século a ofensiva sob o controle da estrutura industrial era muito maior, como foi demonstrado. Em suma, a exportação in natura tem ganhado importância para as empresas transnacionais, pois, além de reduzir os investimentos em capital fixo, tem uma demanda crescente e, no Brasil, um marco regulatório favorável.

Apesar da supremacia do Grupo ABCD, algumas firmas de capital nacional têm se mantido e, um menor número, têm expandido significativamente os seus negócios, figurando dentre as principais empresas do complexo soja. Esse é o caso da Aceitera General Deheza (AGD), Molinos Rio de la Plata e Vicentin na Argentina, que possuem $22,7 \%$ da capacidade de esmagamento e respondem a mais de $30 \%$ das exportações de óleo e farelo (Hinrichsen, 2013; MAGyP, 2013); da Amaggi e, em menor medida, da Caramuru e Imcopa no Brasil, que detêm 10\% da capacidade de esmagamento da soja (ABIOVE, 2013). Além disso, a empresa estatal chinesa Cofco começa a competir de igual para igual com o Grupo ABCD nos dois países após obter, no início de 2014, o controle majoritário da Noble e da Nidera, que atuam na compra de soja em grão e no seu esmagamento.

Outra semelhança que ocorre entre Brasil e Argentina no complexo soja refere-se ao destino desse produto, que segue majoritariamente para exportação à China. Entretanto, existem duas variações importantes. A primeira refere-se ao peso que o consumo 
interno assume sobre a produção total, que é maior no Brasil (absorve $26 \%$ da soja colhida) e menor na Argentina (14,5\%). A segunda diferença está ligada aos subprodutos da soja que são exportados. No Brasil, há uma supremacia da soja em grão (73\%), embora o óleo $(5 \%)$ e o farelo $(22 \%)$ também sejam exportados. Já na Argentina, tem ocorrido uma maior paridade entre os subprodutos exportados (14\% óleo, 30\% grão e 56\% farelo).

\section{CONSIDERAÇÕES FINAIS}

É impressionante o fato de que, apesar das diferentes e particulares trajetórias econômicas, políticas, científico-tecnológicas e jurídico-institucionais de cada país, existem muitos elementos comuns na cadeia da soja no Brasil e na Argentina. Foram poucos os períodos e movimentos que destoaram de um fluxo semelhante e convergente, como é o caso do perfil dos produtores (embora a carência de estudos comparativos impeça a confirmação desse pressuposto). A crescente globalização da cadeia produtiva da soja é, sem dúvida, um elemento-chave que condiciona a elevada similaridade e inter-relação entre Brasil e Argentina. Embora a internacionalização desse mercado exista desde o princípio - sobretudo via preço e demanda externa -, nos últimos anos, ela vem se intensificando cada vez mais por meio da presença de produtores estrangeiros, de empresas transnacionais atuantes em diversas fases da cadeia produtiva, da crescente importância do mercado externo, do investimento de capitais não agrários e estrangeiros na produção de soja etc.

Um elemento interessante é que o Brasil e a Argentina atuam enquanto "polos regionais" do complexo soja no Cone Sul (que também incluí Uruguai, Paraguai e Bolívia). Essa designação não ocorre apenas por concentrarem grande parte da produção de soja, mas por "exportarem" aos países vizinhos muitos atores (agricultores, empresas e cooperativas), tecnologias (OGM, plantio direto etc.) e modelos de produção, de gestão e de políticas públicas. Em relação aos produtores de soja, os brasileiros controlam 90\% da soja no Paraguai (incluem-se nesse cálculo os "brasiguaios") e 40\% na Bolívia, en- 
quanto os argentinos produzem $50 \%$ da soja uruguaia, além de terem grandes grupos em todos os países do Cone Sul (Pérez Luna, 2007; Urioste, 2011; Oyhantçabal e Narbondo, 2011; Revista Exame, 2011). Outra semelhança presente nos dois países analisados referese aos impactos negativos que a expansão da soja tem provocado. Apesar desses elementos não terem sido objetos de análise neste trabalho, vários autores (Dros, 2004; Schlesinger, 2006; Moraes Silva e Melo, 2009; OEA, 2009; Repórter Brasil, 2010; GenØk, 2012; entre outros) destacam as consequências e implicações desse modelo de produção em determinadas regiões, incluindo impactos sociais (concentração da terra e da renda, conflito agrário, intensificação da pobreza, aumento das desigualdades, expulsão de produtores e comunidades tradicionais das suas áreas de origem etc.); ambientais (desmatamento, queimada, uso intensivo de agroquímicos, contaminação do solo e da água, uso de semente transgênica etc.); culturais (principalmente quando ocorre a entrada de produtores de outras regiões, que introduzem novas tradições e, muitas vezes, desqualificam os modos de vida nativos); e econômicos (aumento do preço das terras, redução da diversidade de atividades agropecuárias, primarização das exportações, redução dos empregos gerados, grande dependência das empresas transnacionais etc.).

\section{REFERÊNCIAS}

ABIOVE - Associação Brasileira das Indústrias de Óleos Vegetais. Estatística. 2013. In: http://www.adecoagro.com, acesso em 07 de maio de 2013.

ADECOAGRO. Nuestra Historia. 2013. In: http://www.adecoagro.com, acesso em 15 de maio de 2013.

ANP - Agência Nacional do Petróleo, Gás Natural e Biocombustíveis. Anuário Estatístico Brasileiro do Petróleo, Gás Natural e Biocombustiveis - 2012. Rio de Janeiro: ANP, 2012.

ARBELETCHE, G.; CARBALlO, I. Sojización y concentración de la agricultura uruguaya. In: XXXIV Congreso de la Asociación Argentina de Economía Agrícola Córdoba. Anais... Argentina, 2006. 
BANCO MUNDIAL. Data. 2914. In: http://data.worldbank.org, acesso em 24 de janeiro de 2014.

BCB - Banco Central do Brasil. Anuário Estatístico do Crédito Rural. 2013. In: http://www.bcb.gov.br/htms/CreditoRural/2012, acesso em 28 de junho de 2013.

BELIK, W. Agroindústria e reestruturação industrial no Brasil: elementos para uma avaliação. In: RAMOS, P.; REYDON, B. P. Agropecuária e agroindústria no Brasil: ajuste, situação atual e perspectivas. Campinas: ABRA, 1995. (pp. 107 - 123).

BELL, D. E.; SCOTT, C. Los Grobo: o futuro da agricultura? Harvard Business School, 2010.

BENETTI, M. D. Globalização e desnacionalização do agronegócio brasileiro no pós 1990. Documentos FEE, n. 61. Porto Alegre: FEE, 2004.

BICKEL, U. Brasil: expansão da soja, conflitos sócio-ecológicos e segurança alimentar. 2004. Dissertação (Mestrado em Agronomia Tropical). Programa de Pós-Graduação em Agronomia Tropical Universidade de Bonn, Alemanha, 2004, p. 169.

BOM FUTURO. Institucional. 2013. In: http://www.bomfuturo.com.br, acesso em 02 de julho de 2013.

BRANDÃO, A. S. P.; REZENDE, G. C.; MARQUES, R. W. C. Crescimento agrícola no período 1999/2004: a explosão da soja e da pecuária bovina e seu impacto sobre o meio ambiente. Economia Aplicada, n. 10, pp. 249-266, 2006.

CAMPOS, M. C. O papel do Estado brasileiro na expansão do complexo da soja. In: XII Coloquio de Geocrítica. Anais..., Bogotá, 2012.

CEPEA - Centro de Estudos Avançados em Economia Aplicada. PIB do Agronegócio no Brasil. 2014. In: http://cepea.esalq.usp.br/pib, acesso em 12 de janeiro de 2014.

CIARA - Camara de la Industria Aceitera de la Republica Argentina. Estadisticas del Sector. 2013. In: http://www.ciaracec.com.ar/ciara/ bd/index.php, acesso em 05 de maio de 2013.

COMES. Relatórios de Comércio Exterior. 2013. In: http://trade.nosis.com/ pt/Comex, acesso em 09 de abril de 2013.

CONAB - Companhia Nacional de Abastecimento. Série Histórica de Produção. 2013. In: http://www.conab.gov.br, acesso em 23 de abril de 2013. 
- Sistema de Cadastro Nacional de Unidades Armazenadoras. 2012. In: http://sisdep.conab.gov.br/consultaarmazemweb, acesso em 20 de maio de 2013.

CONTE, A. S. et. al. Oleaginización de la agricultura argentina. In: $\mathrm{V}$ Jornadas Interdisciplinarias de Estudios Agrarios y Agroindustriales. Anais... Buenos Aires, 2009.

DELGADO, G. d. C. A questão agrária no Brasil, 1950-2003. JACCOUD, L.(ed.). Questão social e políticas sociais no Brasil contemporâneo. Brasilia: IPEA, 2005. (pp. 51-90).

DELGADO, N. G.; LEITE, S.; WESZ JUNIOR, V. J. Nota técnica: produção agrícola. Rio de Janeiro/RJ, 2010.

DOUGNAC, G. M. Apuntes acerca de la historia de la soja en la Argentina. Elementos para delinear experiencias comparadas. Documentos del CIEA, Facultad de Ciencias Económicas de la UBA, n. 2, 2004.

DROS, J. M. Manejo del boom de la soja: dos escenarios sobre la expansión de la producción de soja en América del Sur. Amsterdam: AIDEnvironment, 2004.

EMBRAPA - Empresa Brasileira de Pesquisa Agropecuária. Sistema de Produção 6. 2004. In: http://www.cnpso.embrapa.br/download/ publicacao, acesso em 15 de julho de 2013.

FAOSTAT - División de Estadísticas de la Organización de las Naciones Unidas para la Alimentación y la Agricultura. Estadísticas generales. 2013. In: http://faostat.fao.org/, acesso em 29 de abril de 2013.

FARINA, E. M. M. Q.; ZYLBERSZTAJN, D. Competitividade no Agribusiness Brasileiro. IPEA, São Paulo, 1998.

FARM LAND GRAB. Bolivia: Más de un millón de hectáreas en manos de extranjeros. 2011. In: http://farmlandgrab.org/post/view/18366, acesso em 22 de abril de 2013.

FERNÁNDEZ, A. J. C. Sociedade e economia do agronegócio: estudo exploratório do estado de Mato Grosso. Relatório de Pesquisa. Cuiabá/MT, 2009.

GENOK - Centro para la Bioseguridad. Producción de soya en el Cono Sur de las Américas: actualización Sobre el Uso de Tierras y Pesticidas. Virmegraf: Cochabamba/Bolivia, 2012. 
GRAS, C. Los empresarios de la soja: cambios y continuidades en la fisonomía y composición interna de las empresas agropecuarias. Mundo Agrario, v. 12, n. 24, pp. 1 - 32, 2012.

. Expansión agrícola y agricultura empresarial: el caso argentino. Revista de Ciencias Sociales, v. 26, n. 32, pp. 73-92, 2013.

GRISA, C.; WESZ JUNIOR, V. Políticas públicas para a agricultura familiar: entre avanços e desafios. Boletim do OPPA, n.03, pp. 1 - 4, 2010 .

GROSSO, S. et. al. Impactos de los "pools de siembra" en la estructura social agraria. Una aproximación a las transformaciones en los espacios centrales de la Provincia de Santa Fe - Argentina. Revista de Estudios Regionales y Mercado del Trabajo, n. 6, pp. 115-138, 2010.

GRUPO ANDRE MAGGI. Sobre o Grupo. 2013. In: http://www. grupoandremaggi.com.br, acesso em 07 de julho de 2013.

GUIBERT, M. et. al. De Argentina a Uruguay: espacios y actores en una nueva lógica de producción agrícola. Pampa, n. 7, 2011, pp. 13-88, 2011.

HEREDIA, B. M. A.; PALMEIRA, M.; LEITE, S. P. Sociedade e Economia do Agronegócio. Revista Brasileira de Ciências Sociais, v. 25, pp. 159-176, 2010.

HILBERT, J. A. Producción de biodiesel a partir de aceite de soja: contexto e evolución reciente. Buenos Aires: Ediciones INTA, 2012.

HINRICHSEN, J. J. Annual Yearbook on Oilseeds Markets. Buenos Aires, 2013.

IBGE - Instituto Brasileiro de Economia e Estatística. Banco de dados agregados. 2013. In: http://www.sidra.ibge.gov.br, acesso em 18 de julho de 2013.

IMEA - Instituto Mato-Grossense de Economia Agropecuária. Vinte grupos concentram 20\% da área plantada de soja em MT. 2010. In: http://www.imea.com.br/noticias.php?id=217, acesso em 22 de julho de 2013.

INDEC - Instituto Nacional de Estadística y Censos. Agricultora. 2013. In: http://www.indec.gov.ar/agropecuario, acesso em 18 de maio de 2013. 
INFOCAMPO. El Tejar reduce su inversión en siembra. 2013. In: http:// infocampo.com.ar/nota/campo/43243/el-tejar-reduce-su-inversionen-siembra, acesso em 10 de junho de 2013.

INOCÊNCIO, M. E.; CALAÇA, M. Cerrado: fronteira da produção agrícola capitalista do século XX. In: XIX Encontro Nacional de Geografia Agrária. Anais..., São Paulo, 2009.

INTA - Instituto Nacional de Tecnologia Agropecuária. Análisis de la cadena de la soja en la Argentina. Buenos Aires: INTA, 2009.

LA NACIÓN. El Tejar, ante una decisión drástica. 2013. In: http://www. lanacion.com.ar/1574203-el-tejar-ante-una-decision-drastica, acesso em 19 de junho de 2013.

LAVARELLO, P.; GUTMAN, G.; RIOS, P. M. Libéralisation, entreprises transnationales et formes d'insertion internationale: le cas des filières soja et blé en Argentine. In: Regnault, H. (ed.). La reconnexion agricole Nord-Sud. Quels enjeux pour les pays en développement?. Montpellier: CIHEAM, pp. 115-133, 2010.

LEITE, S. P. Padrão de financiamento, setor público e agricultura no Brasil. In: LEITE, S. (org). Políticas Públicas e Agricultura no Brasil. Porto Alegre, Ed. da UNIVERSIDADE, 2001. (pp. 55-96).

LISSI, J. G.; LOSI, L. I. La evolución del sector agropecuario en Argentina (1860 - 2009). Dimensión Económica, n. 4, 2010.

LOS GROBOS. El grupo Los Grobo pone en marcha una fábrica de pastas para exportar a Brasil. 2012. In: http://www.losgrobosgr. com.ar/comunicacion/novedades/549-el-grupo-los-grobo-pone-enmarcha-una-fabrica-de-pastas-para-exportar-a-brasil.html, acesso em 4 de junho de 2013.

MAGyP - Ministerio de Agricultura, Ganadería y Pesca. Sistema integrado de información agropecuaria. 2013. In: http:/www.siia.gov.ar/ index.php, acesso em 03 de junho de 2013.

MAPA - Ministério da Agricultura, Pecuária e Abastecimento. AgroStat. 2013. In: agrostat.agricultura.gov.br, acesso em 07 de junho de 2013.

MATTEI, L. Evolução do crédito do PRONAF para as categorias de agricultores A e A/C entre 2000 e 2010. In: Congresso da Sociedade Brasileira de Economia, Administração e Sociologia Rural, 49, 2011, Belo Horizonte (MG), Anais... Belo Horizonte (MG): SOBER, 2011. 
MECON-MinisteriodeEconomiayFinanzasPublicas. Complexooleaginoso.

Serie Producción Regional por Complejos Productivos, Buenos Aires, 2011.

OEA - Organización de los Estados Americanos. Evaluación regional del impacto en la sustentabilidad de la cadena productiva de la soja: Argentina - Paraguay - Uruguay. Departamento de Desarrollo Sostenible de la Organización de los Estados Americanos, 2009.

ONCCA - Oficina Nacional de Control Comercial Agropecuario. Estratificación de productores de soja. 2008. In: http://www.oncca. gov.ar/principal.php?nvx_ver=2388, acesso em 22 de junho de 2013.

OYHANTÇABAL, G.; NARBONDO, I. Radiografia del agronegocio sojero: descripción de los principales atores y los impactos socioeconómicos en Uruguay. Montevideu: Redes, 2011.

PENGUE, W. Producción agroexportadora e (in)seguridad alimentaria: el caso de la soja en Argentina. Revista Iberoamericana de Economía Ecológica, v. 1, pp. 46-55, 2004.

PÉREZ LUNA, M. No todo grano que brilla es oro: un análisis de la soya en Bolivia. CEDLA: La Paz, Bolivia, 2007.

PIERRI, J. El desempeño de las grandes empresas y las cooperativas en la "sojización". Los casos de Cargill y de la Asociación de Cooperativas Agrarias. Documentos del CIEA, Facultad de Ciencias Económicas de la UBA, n. 3, pp. 69 - 95, 2008.

. El boom de la soja. Un retorno al pasado? Realidad Económica, n. 219, pp. 53-63, 2006.

QUEIROZ, F. A. Impactos do comércio internacional de soja sobre a biodiversidade do Cerrado. In: II Encontro da Associação Nacional de Pós-Graduação e Pesquisa em Ambiente e Sociedade. Anais..., São Paulo, 2004.

RALLY DA SAFRA. Grupo Bom Futuro é o Produtor da Década. 2013. In: http://www.rallydasafra.com.br/2013/diario_bordo.asp, acesso em 29 de julho de 2013.

REBORATTI, C. Un mar de soja: la nueva agricultura en Argentina y sus consecuencias. Revista de Geografia Norte Grande, n. ${ }^{\circ}$ 45, pp. 63-76, 2010.

REVISTA EXAME. O Paraguai é movido a soja. 2011. In: http://exame. abril.com.br/revista-exame/edicoes/0986/noticias/movido-asoja?page $=1$, acesso em 26 de abril de 2013 . 
SCHAVARZER, J.; TAVOSNANSKA, A. El complexo sojero argentino. Evolución y perspectivas. Documento de Trabajo, n. 10, Centro de Estudios de la Situación y Perspectivas de la Argentina, 2007.

SCHLESINGER, S. O grão que cresceu demais: a soja e seus impactos sobre a sociedade e o meio ambiente. Rio de Janeiro: FASE, 2006.

SECEX - Secretaria de Comércio Exterior. Indicadores e Estatísticas de Comércio Exterior. 2013. In: http://www2.desenvolvimento.gov.br/ sitio/secex/secex, acesso em 27 de julho de 2013.

SLC AGRÍCOLA. A empresa. 2013. In: http://www.slcagricola.com.br/, acesso em 23 de julho de 2013.

SOUZA, J. F. D. de. Integração vertical e financeirização: o caso da agroindústria processadora de grãos no Brasil. 2007. Dissertação (Mestrado em Engenharia de Produção). Programa de PósGraduação em Engenharia da Produção - Universidade de São Paulo. São Paulo/SP, p. 145.

TEUBAL, M. Expansión del modelo sojero en la Argentina: de la producción de alimentos a los commodities. Realidad Económica, n. 220, pp. 71-96, 2006.

URIOSTE, M. Concentración y extranjerización de la tierra en Bolivia. Fundación TIERRA: La Paz, Bolivia, 2011.

USDA - U.S. Department of Agriculture. Data and Statistics. 2014. In: www.usda.gov/l, acesso em 02 de julho de 2013.

VALOR ECONÔMICO. Dez grupos têm um terço da nova fronteira da soja. 2013. In: http://www.valor.com.br/empresas/3067336/dezgrupos-tem-um-terco-da-nova-fronteira-da-soja, acesso em 03 de maio de 2013.

VANGRUARDA AGRO. Empresa. 2013. In: http://www.grupoligna.com. br/vanguarda-agro, acesso em 06 de julho de 2013.

WARNKEN, P. F. Política e programas: o setor da soja no Brasil. Revista de Política Agrícola, Ano VIII, n. 02, pp. 40-55, 1999.

WEDEKIN, I. A política agrícola brasileira em perspectiva. Revista de Política Agrícola. Ano XIV - Edição Especial, pp. 17-32, 2005.

WESZ JUNIOR, V. J. Dinâmicas e estratégias das agroindústrias de soja no Brasil. Rio de Janeiro: E-papers, 2011.

WESZ JUNIOR, V. J. O mercado da soja e as relações de troca entre 
produtores rurais e empresas no Sudeste de Mato Grosso (Brasil). 2014. Tese (Doutorado em Ciências Sociais). Programa de PósGraduação de Ciências Sociais em Desenvolvimento, Agricultura e Sociedade. Universidade Federal Rural do Rio de Janeiro, Rio de Janeiro/RJ, p. 225.

WILKINSON, J. The Globalization of agribusiness and developing world food systems. In: MAGDOFF, B.; TOKAR, B. Agriculture and Food in Crisis. Monthly Review Press, 2010. (pp. 38-50).

WILKINSON, J.; WESZ JUNIOR, V. J. Underlying issues in the emergence of China and Brazil as major global players in the new South-South trade and investment axis. International Journal of Technology Management \& Sustainable Development, v. 12, n. 3, pp. 245-260, 2013.

Recebido: 19/05/2014.

Aprovado: 1\%07/2014. 